\title{
Eugenio María de Hostos oder die karibische Wallfahrt
}

Mit Eugenio María de Hostos treffen wir auf einen puerto-ricanischen Intellektuellen und Schriftsteller, der durch seine vielfältigen Aktivitäten und Talente hervorsticht sowie über einen beeindruckenden vielkulturellen Bildungshorizont verfügt. Am 11. Januar 1839 im Ostteil seiner Heimatinsel in eine wohlhabende Familie geboren, verbrachte er die entscheidenden Jahre seiner Ausbildung und Bildung in Spanien, bevor er in der Folge eine wahre Pilgerschaft durch verschiedene Länder Amerikas antrat. Sie führte ihn von den Vereinigten Staaten im Norden über seine Heimat Puerto Rico und Santo Domingo in die Karibik sowie über Venezuela und Brasilien bis hinunter nach Peru, Chile und Argentinien. Er gehört zweifellos in die Gruppe jener lateinamerikanischen Intellektuellen, welche die Vielfalt der Kulturen des Kontinents aus nächster Nähe selbst erleben konnten. ${ }^{1}$

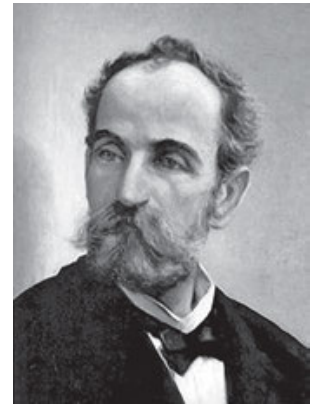

Abb. 60: Eugenio María de Hostos (Mayagüez, Puerto Rico, 1839 Santo Domingo, Dominikanische Republik, 1903).

Nicht weniger weitreichend sind seine beruflichen, intellektuellen und schriftstellerischen Aktivitäten, von denen wir im Rahmen unserer Vorlesung nur einen kleinen Teil kennenlernen können. Eugenio María de Hostos ist berühmt geworden als Begründer der Soziologie in Lateinamerika, auch wenn mir nicht ganz einleuchten will, dass manche Literaturwissenschaftler ihn als Begründer einer lateinamerikanischen Soziologie bezeichnen. Er hat in seinem Leben eine Vielzahl politischer Abhandlungen verfasst, philosophische Essays publiziert, Literaturkritik geschrieben, seine Projekte als Pädagoge nicht nur theoretisch konzipiert, sondern teilweise auch in der Praxis realisiert und erprobt. Darüber

1 Vgl. hierzu Ainsa, Fernando: Hostos y la unidad de América Latina: raíces históricas de una utopía necesaria. In: Cuadernos Americanos 16 (1989), S. 67-88. 
hinaus widmete er sich insbesondere der Frauenbildung und unterbreitete $\mathrm{zu}$ diesem Thema zahlreiche Verbesserungsvorschläge.

Der puerto-ricanische Schriftsteller darf insgesamt als Verkörperung jenes Intellektuellentyps gelten, der eigentlich etwas später in lateinamerikanischen Ländern in Erscheinung tritt und sich in besonders ausgeprägter Form im letzten Drittel des 19. Jahrhunderts und im Bannkreis des Modernismo herauszukristallisieren scheint. Denken wir nur an Figuren wie den Kubaner José Martí oder den Uruguayer José Enrique Rodó, mit deren Werken wir uns noch auseinandersetzen werden!

In der Tat verbindet sich das Lebenswerk des weitaus älteren Hostos, der am 11. August 1903 in Santo Domingo verstarb, mit beiden Figuren der großen Modernisten auf unterschiedliche, doch fruchtbare Weise. Ebenso wie José Martí für die Unabhängigkeit der Antillen von Spanien eintretend, hat Hostos noch in seinen letzten Jahren das Erscheinen von Rodós Ariel gefeiert und die Rezeption dieses kleinen Bändchens aus Uruguay gerade auch im karibischen Raum gefördert. Eugenio María de Hostos war der große Vermittler von Ariel an die dominikanischen Brüder Pedro und Max Henríquez Ureña, die dann der Gedankenwelt von Hostos und Rodó nicht nur in Santiago de Cuba, sondern bald auch in Mexiko im Ateneo de la Juventud zunächst vereinzeltes Gehör und schließlich dem später so einflussreichen Band breiteren Zugang in die lateinamerikanischen Intellektuellenkreise verschafften. Auch wenn sich Hostos' fraglos einflussreichstes Werk noch in der Mitte des 19. Jahrhunderts ansiedelt, so ist seine gesamte intellektuelle Gestalt doch eine Brückenfigur hinüber ins 20. Jahrhundert Lateinamerikas.

Eugenio María de Hostos darf vor diesem Hintergrund als Vermittler zwischen Romantik und hispanoamerikanischem Modernismus, zwischen Literatur und Soziologie, zwischen Philosophie und Politik, zwischen Pädagogik und Literaturkritik gelten, vor allem aber als jener Intellektuelle, der den Übergang der Karibikinseln Puerto Rico und Kuba von der spanischen Kolonialherrschaft zur Herrschaftssphäre der Vereinigten Staaten stets kritisch und teilweise brillant begleitete. ${ }^{2}$ Der puerto-ricanische Schriftsteller ist - und dies ist wichtig - zusammen mit José Martí wohl jene Literatenfigur, welche die weitgespanntesten Talente und Interessengebiete so miteinander zu verbinden verstand, dass all diese verschiedenen Bereiche in einem großartigen Lebenswerk zusammenflossen. Trotz einer oft heterogen wirkenden Zerstückelung in einzelne Bereiche entstand auf diese Weise ein zusammengehöriges, ja homogen wirkendes Werk seines ganzen

2 Vgl. Villanueva Collado, Alfredo: Eugenio María de Hostos ante el conflicto modernismo / modernidad. In: Revista iberoamericana (Pittsburgh) 162-163 (enero - junio 1993), S. 21-32. 
Lebens, innerhalb dessen die unterschiedlichsten Facetten eine bemerkenswerte Einheit bilden.

Als eigentlicher Schriftsteller - wenn auch nicht als Soziologe, Pädagoge oder Philosoph - ist der Puerto-Ricaner von Kritik und Literaturwissenschaft recht spät entdeckt worden. Und doch war diesem Bereich gerade auch sein frühes Schaffen gewidmet. Nach einer Reise 1862 von Spanien, wo der junge Hostos seine akademische Ausbildung erfuhr und sich erstmals für Politik interessierte, nach Puerto Rico reifte bei einem mehrmonatigen Aufenthalt in der kolonialspanischen Atmosphäre seiner Heimatinsel der Plan, einen Roman zu schreiben, in dem die untragbare Problematik dieser politischen Situation herausgearbeitet und Spaniens Kolonialstil angeklagt werden sollte. Das gewählte Medium hierzu war die Literatur, schlimmer noch: der Roman! Auch in diesem Falle bildete mithin diese so mobile und facettenreiche literarische Gattung das Vehikel für einen politischen Bewusstwerdungsprozess und (letztlich gescheiterten) Unabhängigkeitskampf einer Insel, welche heute -wie Sie wissen - zu den Vereinigten Staaten von Amerika gehört.

Dies freilich war ein keineswegs ungewöhnliches Verfahren, werden Sie nun sagen und mit Recht auf die in unserer Vorlesung bereits besprochenen Romane verweisen, hatte doch gerade die hispanoamerikanische Romantik in Fortsetzung einer aufklärerischen Tradition Literatur als Waffe im Kampf um gesellschaftliche Veränderungen begriffen. Und doch verhalten sich die Dinge bei Hostos anders: Denn er misstraut der Literatur, misstraut der Imagination, die den Gegenpol zur Ratio, zum Verstandesmäßigen, zum Logischen darstellt, das für Hostos stets den Vorrang besitzen musste und für ihn eine höhere Entwicklungsstufe verkörpert. Dieses Unwohlsein im Kreise der Fiktion verbindet den Puerto-Ricaner einmal mehr mit dem kubanischen Intellektuellen José Martí, dessen Romane Amistad funesta oder Lucía Jerez bei allen literarischen Besonderheiten freilich nicht die literarische Qualität des Romans von Hostos erreichten. ${ }^{3}$

Mit La peregrinación de Bayoán haben wir es also mit einem Roman zu tun, der von einem Autor verfasst wurde, der - wenn auch vor allem in späteren Jahren Literatur kritisch beobachtete, ja verurteilte und zudem versuchte, sie vor allem aus der beherrschenden Position innerhalb des Bildungssystems seiner Zeit zu verdrängen. Dabei war er freilich nicht der einzige, sprachen sich doch zahl-

3 Vgl. Ette, Ottmar: „Cierto indio que sabe francés“: Intertextualität und literarischer Raum in José Martís „Amistad funesta“. In: Iberoamericana (Frankfurt am Main) IX, $25-26$ (1985), S. $42-$ 52; sowie (ders.): „Cecilia Valdés“ y „Lucía Jerez“: cambios del espacio literario en dos novelas cubanas del siglo XIX. In: Balderston, Daniel (ed.): The Historical Novel in Latin America. A Symposium. Gaithersburgh: Hispamérica 1986, S. 85-96. 
reiche spanische und lateinamerikanische Intellektuelle der zweiten Hälfte des 19. Jahrhunderts für ein Zurückdrängen des großen Einflusses der Literatur aus dem Bildungssektor aus. Es ist eigenartig, dieses Bemühen von einer geschichtlichen Position aus zu bewerten und zu deuten, in welcher die Literatur in erheblichem Maße heute aus dem Bildungskanon der - wie es früher hieß - , höheren Lehranstalten' verdrängt worden ist. Dass für diese weitgehende Verdrängung ein hoher gesellschaftlicher Preis zu entrichten ist, zeigt sich bereits seit einiger Zeit sehr deutlich. Dennoch wird es, so fürchte ich, noch etwas länger dauern, bis in anderer Form die Literaturen der Welt wieder notwendig an die Schulen zurückkehren können, nicht länger getragen vom Pathos oder der scheinbaren Selbstverständlichkeit einer nationalen (Literatur-)Geschichte.

Als La Peregrinación de Bayoán 1863 in Madrid erschien, war der junge Mann gerade mal vierundzwanzig Jahre alt - und grundlegend von der (ersten) Reaktion auf seinen Roman enttäuscht. In Madrid wurde die darin enthaltene Anklage Spaniens und des spanischen Kolonialismus mit eisigem Schweigen aufgenommen; und auf Puerto Rico, wohin Hostos viele Exemplare hatte verfrachten lassen, dauerte es nicht lange, bis die Kolonialbehörden den Text verboten. Man sprach also nicht von La Peregrinación de Bayoán, jenem Roman, der später als das eigentliche Hauptwerk des puerto-ricanischen Autors angesehen werden sollte. An diesen ersten Reaktionen änderte zwar vieles die zweite Ausgabe, welche zehn Jahre später - also 1873 - vom Autor in Santiago de Chile veröffentlicht sowie mit einem Vorwort versehen wurde; und deren Lektüre allen Leserinnen und Lesern des Romans anzuraten ist. Doch konnte letztlich auch in Chile, am anderen Ende der Welt Lateinamerikas, der Roman seine Wirkkraft nicht entfalten. Erst im Jahre 1939 sollte eine weitere Auflage erfolgen, welche ein breiteres Publikum erreichte; doch noch heute ist die Forschungsliteratur zu diesem Roman erst stockend in Gang gekommen. Mir scheint es gleichwohl wichtig, Sie mit diesem in Spanien verfassten puerto-ricanischen Roman etwas näher bekannt zu machen.

Bevor wir uns mit dem Romantext und der Handlung des Romans selbst beschäftigen, sollten wir uns - in dieser Vorlesung fast schon eine gute Gewohnheit - zunächst mit dem Vorwort zur zweiten Ausgabe auseinandersetzen. Sagen wir es so: Es ist ein wahres Meisterwerk an Vorwort! Damit konnte der Autor an dessen auf Juni 1873 datiertem Ende die Worte niederschreiben: „Terminada la historia, empieza el libro“4 - die Geschichte ist beendet, nun beginnet das Buch.

4 Hostos, Eugenio María de: La Peregrinación de Bayoán. Novela. In (ders.): Obras Completas. Bd. VIII. La Habana: Editorial Comercial 1939, S. 32. 
Es ist nicht nur die Geschichte des Buches selbst, welches die Leserin oder der Leser in die Hand genommen hat; es ist auch eine kurze Geschichte von Eugenio María de Hostos sowie eine Geschichte im allgemeinsten Sinne. In diesem Zusammenhang ist aufschlussreich, wie die Erzählerinstanz des Vorworts - die nicht mit dem realen Autor Eugenio María de Hostos zu verwechseln ist - den eigenen Ort des Buches zu umschreiben versucht. Nicht zuletzt wendet sich diese Erzählerinstanz an die Jugend Amerikas, für die das Buch ein gutes Beispiel geben solle; ${ }^{5}$ eine literarische Geste, die wir in Rodós Ariel wiederfinden werden. Nicht umsonst sind Hostos und der Magier Próspero aus Rodós berühmtestem Werk Pädagogen und Lehrmeister, „Maestros“, die nach dem jungen Lesepublikum schielen, das ihre Lehren und Meinungen in die Tat umzusetzen befähigt ist.

So wendet sich die Erzählerinstanz in der ersten Person Singular nicht ohne Stolz an ihre Leserschaft, auch wenn sie für die „obras de imaginación“, also für die Werke von Einbildungskraft und Fiktion wenig Achtung übrig hat. ${ }^{6}$ Eine ganze Bibliothek wird aufgestellt, die Rückschlüsse auf die transatlantischen Asymmetrien zulässt: Johann Wolfgang Goethes Werther und Ugo Foscolos Ultime Lettere di Jacopo Ortis sind gelesen, daneben auch der gesamte Lord Byron und sämtliche Werke von José de Espronceda, wobei die Schriften der beiden letztgenannten Romantiker als „peligrosas influencias sociales“,7 mithin als gesellschaftlich gefährdend erkannt und demaskiert sind. Eine Abkehr von der Romantik beginnt sich abzuzeichnen: Denn gegen diese wirke nur das Gegengift der Moralisten aller Zeiten.

Hostos ist schon als junger Mann kein begeisterter und schon gar kein ,reinrassiger' Romantiker mehr, zumindest kein europäischer Romantiker: All diese Autoren Europas müssen Federn lassen, doch lateinamerikanische Autoren werden zunächst einmal nicht erwähnt. Damit wird der literarische Raum aufgespannt, der diesem puerto-ricanischen Roman zu Grunde liegt. Zu ihm gehören auch der US-amerikanische Historiker William H. Prescott, der französische Aufklärer Guillaume-Thomas Raynal und manch andere Vertreter nicht der „Belleslettres“, sondern einer pragmatisch-didaktischen, stets gesellschaftsbezogenen Prosa, die in politisch und sozial interessierten Kreisen verbreitet war.

Genau an dieser Stelle schreibt sich unser Autor intertextuell ein, wobei er unverkennbar der europäischen Literatur, insbesondere aus Frankreich und England, sein Hauptaugenmerk widmet. Dass die Romantik aber nicht ferne ist, zeigt die Inszenierung der Entstehung des Buches aus der Erfahrung von 1862,

5 Ebda., S. 6.

6 Ebda.

7 Ebda., S. 7. 
als er bemerkt habe, wie sehr seine Heimat von der Kolonialmacht Spanien tyrannisiert sei und wie wichtig es wäre, dagegen etwas zu unternehmen - und sei es, dagegen etwas zu schreiben. So kommt ihm die Idee eines Buches, die er dem spanischen Schriftsteller Rada y Delgado anvertraut; aber so, als habe er dieses Buch bereits geschrieben. Der Spanier will daraufhin das Buch sehen, wird jedoch für einen Augenblick um Geduld gebeten, denn gleich werde er etwas zu lesen bekommen:

Ich drückte ihm irgendein Buch in die Hand, bat ihn zu warten und ließ ihn in einer meiner beiden Zimmer alleine, ging selbst aber ins andere. Ich nahm Feder, Tinte, Papier und schrieb.

Nach einer halben Stunde kam ich strahlend vor Freude wieder heraus und schrie: Hier ist das Buch, ich las Rada die ersten sechs Tagebücher von La Peregrinación de Bayoán vor.

Rada wollte mehr lesen und versteifte sich immer stärker darauf, mehr lesen zu können. Als ich ihm sagte, dass es nicht mehr gebe, war er verblüfft. Und als ich sagte, dass das Gelesene gerade erst geschrieben worden sei, war die Verwunderung, die er an den Tag legte, meine Belohnung und mein Ansporn.

Ja schon, aber das Buch?, insistierte er. [...]

Morgen.

Das ist unmöglich.

Sie werden ja sehen. Mechanisch gesehen ist es unmöglich, dass ich dieses Buch in vierundzwanzig Stunden schreibe, aber intellektuell ist es möglich, da ich es gerade in meinem Gehirn konzipiert und geschrieben habe. ${ }^{8}$

Ja, so schnell geht das mit der Literatur: Man holt einfach Feder, Tinte und Papier - und schon geht es los; dies ist die romantische Geste, die der Inspiration, des unvorbereiteten Einströmens des Geistes quasi in die Feder. Eine halbe Stunde nur, und schon sind die ersten sechs Tagebucheinträge perfekt! Ob all dies glaubwürdig ist, mag man bezweifeln. Doch wird an dieser Szene - eine wahre Inszenierung der Geburtsszene des Buches und der Konzeption im gebärenden Sinne - auch noch etwas anderes deutlich: die deutliche Bewegung weg von der Romantik; denn das Buch, innerhalb von vierundzwanzig Stunden geradezu spontan ersonnen, ist - wenn Sie mir den Ausdruck gestatten - eine Kopfgeburt. Das Gehirn, der „cerebro“ ist das entscheidende menschliche Organ: Wir dürfen diese Literatur daher auch als zerebral verstehen.

Wir haben es mit keinem romantischen Literaten mehr zu tun, der seine Feder in das eigene Herzblut taucht und die Schrift in eine erkaltete, geronnene Her-

8 Hostos, Eugenio María de Hostos: La Peregrinación de Bayoán, S. 9. 
zensschrift verwandelt. ${ }^{9}$ Nein: Schreiben geschieht im Kopf, bevor es mühsam auf dem Papier mechanisch nachvollzogen wird! Nicht die Herzensschrift muss nachgezeichnet werden, sondern die Schrift im Kopf, die zerebrale Schrift. Der Kopf ist Arbeitsfläche wie Entstehungsort des Buches und nicht etwa das Herz der Romantiker.

So sehen wir an der Inszenierung der Entstehung jenes Buches, das der Leser bereits in die Hand genommen hat, zehn Jahre nach dessen Erstveröffentlichung deutlich, wie sich Hostos noch in den Gesten der Romantik, aber nicht mehr an ihren Schreiborten bewegt. Hostos' Literatur inszeniert sich als eine zerebrale Literatur, intellektuell konzipiert. Ihr Körper-Ort ist der Kopf, und diesem Entstehungsort entspricht auch der Ort, auf den sie einwirken soll: auf den Kopf, das Denken des Lesepublikums. Das Leben, so heißt es wenig später in autobiographischem Gestus, ${ }^{10}$ sei für die Ich-Figur stets die Realisierung des Gedachten im Leben gewesen. So ist das Leben die zweite und extrem wichtige Dimension des Schreibens, der Literatur.

Es handelt sich um Zerebrales, das in die Wirklichkeit und vielleicht mehr noch in das real gelebte Leben direkt umgesetzt wird: Die pädagogische und zugleich pragmatische Dimension eines solchen Schreibens wird von Beginn an offenkundig. Die Ideale sind nicht aus dem Text verschwunden, doch sind es nicht mehr jene der Romantiker. Ziel ist es nun (und zwar ein im Leben erreichbares Ziel), ein logischer Mensch zu werden, ein „hombre lógico“. ${ }^{11}$ Da erscheint es nur logisch, dass der Roman sich in eine solche Logik gesellschaftlichen Wirkens, sozialer Wirkungskraft einfügen muss.

Um wirken zu können, so folgert der Autor, muss man in der Literatur einen Namen haben. Die Eroberung eines literarischen Namens sei gleichbedeutend mit der Eroberung einer bestimmten Macht; ${ }^{12}$ einer Macht, die Voraussetzung des wirkungsvollen Einsatzes für das unterdrückte, gedemütigte Vaterland ist. Eugenio María de Hostos erkannte sehr präzise und lange vor Michel Foucault, was ein literarischer Autor ist und welche Funktion seinem Namen zukommt. ${ }^{13}$ Auf die Gefahr, ein wenig anachronistisch daherzukommen: Das ist soziologisch gedacht und erfasst - geradezu feldsoziologisch - nicht nur die Zusammenhänge zwischen dem Feld der Literatur und dem der Macht, sondern entwickelt auch

9 Vgl. Schneider, Manfred: Die erkaltete Herzensschrift. Der autobiographische Text im 20. Jahrhundert. München - Wien: Hanser 1986.

10 Hostos, Eugenio María de: La Peregrinación de Bayoán, S. 10.

11 Ebda.

12 Ebda., S. 12.

13 Vgl. Foucault, Michel: Was ist ein Autor? (Qu'est-ce qu'un auteur?). In (ders.): Schriften zur Literatur. Frankfurt am Main - Berlin - Wien: Ullstein 1979, S. 7-31. 
Karrierestrategien zur Besetzung wichtiger Positionen im entsprechenden Feld. Mit romantischer Geste wird im selben Atemzug die Umsetzung eines derartigen Kalküls anlässlich der Veröffentlichung dieses Romanerstlings wieder zurückgenommen - und man bemerkt, dass der Autor sich auch auf dieser Ebene noch ganz in seinem eigenen Entwicklungsprozess befindet.

Das Vorwort von 1873 berichtet, wie wenig der Autor all jene Chancen genutzt habe, das Schweigen $\mathrm{zu}$ durchbrechen, das ihm in Madrid als spanienfeindlichem karibischen Autor entgegengeschlagen sei. Schreiben kann Macht sein, aber auch Ausdruck von Ohnmacht angesichts gesellschaftlicher Verhältnisse, die sich - zumindest vorerst - einen feuchten Kehricht um vollgeschriebenes Papier kümmern. Daran hat sich auch in unserer Epoche nichts geändert: Schreiben zielt auf Veränderungen, die langfristiger Natur sind. Für kurzfristige politische Prozesse sind andere Instanzen und Institutionen weitaus wichtiger. Auch daher rührt das Unwohlsein von Hostos hinsichtlich der fiktionalen Gattung des Romans.

Doch der puerto-ricanische Autor entschied sich damals für diese Gattung. Das Buch sollte den aktiven Zweifel in der Gestalt Bayoáns vorführen und die Kolonialmacht Spanien anprangern und verurteilen. Literatur als Tribunal: Die Geschichte sollte, um einen berühmt gewordenen Satz aus der kubanischen Historie umzudeuten, Eugenio María de Hostos freisprechen. Denn das Ziel, die Befreiung der Antillen von spanischer Unterdrückung und Herablassung zu erreichen, ist dem Roman von Beginn an eingeschrieben.

Glücklicherweise gilt für La Peregrinación de Bayoán nicht, dass man mit den besten Absichten die schlechteste Literatur macht. Im Vorwort von 1873 zur zweiten Edition des ursprünglich im November 1863 erschienenen Buches heißt es unmissverständlich - und die kommende Unabhängigkeitsrevolution, die sogenannte „Guerra de Diez Años“, war seit 1868 bereits vollständig entbrannt:

So wurden in einer logischen Verkettung von Ideen die beiden Aspekte miteinander verbunden, die ich wahrgenommen hatte, und mir schien, dass das ganze Buch, dass all seine Intentionen, dass all sein Widerwille wie eine einzige fulminante Anklage gegen Spanien sein würde.

Von einer Recht schaffenden Feder angeklagt, würde das Weltbewusstsein Spanien verurteilen. Von einem überzeugenden Patriotismus angeklagt, würden alle Patrioten der Antillen Spanien verfluchen.

Von der Verfluchung zur Explosion, ein einziger Schritt!

Ich hatte den ersten unternommen, ich konnte den zweiten folgen lassen. ${ }^{14}$

14 Hostos, Eugenio María de Hostos: La Peregrinación de Bayoán, S. 17 f. 
Damit wird eine gesellschaftspolitische Brisanz erkennbar und zugleich ein Glaube an die politische Sprengkraft dieses Romans, die den heutigen Leser, die heutige Leserin erstaunen, vielleicht gar in Verblüffung versetzen. Die romantische Liebesgeschichte, die im Mittelpunkt des Handlungsgeschehens von La Peregrinación de Bayoán steht, soll den Sprengstoff für einen Unabhängigkeitskrieg enthalten? Kein Zweifel: Eugenio María de Hostos vertraute auf diese politisch revolutionäre Funktion, und die Neuveröffentlichung im Jahre 1873 setzte hier ein deutliches Zeichen! Denn sie kann als fiktionaler, romanesker Beitrag dafür gewertet werden, den aktuellen Befreiungskampf zu unterstützen und die spanische Kolonialherrschaft endgültig abzuschütteln.

Es ist uns aus der Geschichte bekannt, dass dies noch nicht in den siebziger, wohl aber dann - wenn auch für Puerto Rico mit anderen Konsequenzen - in den neunziger Jahren des 19. Jahrhunderts gelang. Spanien verschwand als Kolonialmacht, wurde aber - wie sich aus der historischen Rückschau zeigt - durch die Vereinigten Staaten ersetzt. Immerhin wurde es als Machtfaktor ein für alle Mal ausgeschaltet, ebenso auf den Antillen wie auf den Philippinen (die wir uns noch mit einem literarischen Beispiel näher anschauen werden). Die politische Sprengkraft des Romans von Eugenio María de Hostos lässt sich dabei freilich nicht nachweisen.

Belegen aber lässt sich schon eher die politische Durchsetzungs- und Wirkungskraft seines Autors, stellt Eugenio María de Hostos doch vor José Martí geradezu die idealtypische Verkörperung einer Synthese von Literatur und Politik, von Militanz und Kontemplation, von Pädagogik und Philosophie, von gesellschaftspolitischem Engagement, Freiheitswille und literarischer Aktivität dar. Er darf als Inbegriff des karibischen Intellektuellen im Übergang von der Romantik zur neuen, vom Modernisierungsschub im letzten Drittel des Jahrhunderts ausgelösten gesellschaftlichen und literarischen Situation gelten. Sein Leben im Exil, seine Pilgerschaft durch eine Vielzahl unterschiedlicher Länder des Kontinents, wie wir mit dem Titel seines einzigen Romans sagen könnten, sprechen in diesem Zusammenhang eine deutliche Sprache. Wir werden mit José Rizal bald ein weiteres Beispiel für einen weltgewandten und welterfahrenen Intellektuellen kennenlernen; diesmal freilich aus dem asiatischen Bereich, den damals ebenfalls mit Spanien im Unabhängigkeitskampf befindlichen Philippinen.

Literatur ist für den Puerto-Ricaner Hostos nicht nur eine Art individuelles, sondern vor allem ein kollektives Gewissen, ein öffentlicher Beleg für den Freiheitswillen seines Volkes, dessen fortgesetzte Abhängigkeit er als Teilnehmer jener Verhandlungen in Washington noch miterleben sollte, die nach Ende des Spanisch-Kubanisch-US-Amerikanischen Krieges die Abhängigkeit seiner Insel, nunmehr von den USA, fortschrieben und besiegelten. Puerto Rico zeigt vor diesem historischen Hintergrund das Beispiel einer tragisch gescheiterten Natio- 
nenbildung; eines Prozesses, der im Gegensatz zu Kuba und Santo Domingo, jenen Inseln, die im Roman allegorisch repräsentiert werden und deren Einheit Hostos so sehr betonte, nicht zu eigenständigen politischen Strukturen führte. Das ist gewiss weder die Schuld von Hostos noch seines Romans La Peregrinación de Bayoán, mit dem wir uns nach diesen einführenden Überlegungen nun näher beschäftigen wollen.

Eugenio María de Hostos hatte - wie wir sahen - mit seinen politischen Intentionen nicht hinterm Berg gehalten, sondern sie offen thematisiert. Er sprach in aller Direktheit von seinen anti-spanischen Absichten, ähnlich wie zum gleichen Zeitpunkt etwa der junge José Martí, der von seiner Heimatinsel Kuba nach Spanien verbannt worden war und nun in Madrid für die Unabhängigkeit $\mathrm{zu}$ werben (und $\mathrm{zu}$ agitieren) versuchte. Ihre universitäre Ausbildung erhielten Hostos wie Martí im spanischen Mutterland.

Dem Roman ist ein Verzeichnis indianischer Benennungen vorgeschaltet, um dem Leser die Namenswahl verständlich zu machen. Von Beginn an ist zumindest auf den ersten Blick die indigene Dimension als kultureller Bezugspunkt folglich präsent. Die wichtigsten Protagonisten des Romans - und bisweilen auch ihre karibische Heimat, die selbst in der heutigen Bezeichnung „Karibik“ noch immer die wehrhaften Kariben im Namen führt - tragen indianische Namen, auch wenn sie keinesfalls indianischen Ursprungs sind. Bayoán, der erste, der an der Unsterblichkeit der Spanier zweifelte; Guarionex, jener Kazike, der auf seiner Insel Haití die Spanier bekämpfte; und Marién, die für die Region Mariel auf Kuba steht: Sie alle repräsentieren die Einheit der spanischsprachigen und politisch von Spanien abhängigen Karibik, deren literarische Zusammengehörigkeit als kulturelle Area wir im Rahmen unserer Vorlesung deutlich wahrnehmen können.

Diese drei symbolhaften Gestalten sind Vertreter, in gewisser Weise sogar Personifizierungen ihrer jeweiligen Insel, ${ }^{15}$ und als solche stehen sie in erstaunlichem Kontrast zu ihren Namen: Sie sind nicht nur keine Indianer, sondern denken nicht im Traum daran, indianische Kultur als kulturelle Ausdrucksform in ihr Lebensgefühl oder Kulturverständnis einzubringen. Die indianischen Namen stehen nur für Kampf und Widerstand gegen Spanien, nicht für jene Kultur der Zukunft, die in La Peregrinación de Bayoán so häufig beschworen und in Amerika verankert wird. Auch die Kultur der Schwarzen beziehungsweise der Sklaven - allen abolitionistischen Verweisen und kurzen Ausführungen zum Trotz - erscheint nie als Bestandteil einer künftigen Kultur im karibischen Raum. So gilt es zunächst einmal deutlich zu akzentuieren, dass der Roman von Eugenio María de Hostos unverkennbar am ersten Pol unseres kulturellen Kräftefeldes ausgerichtet ist und

15 Explizit ebda., S. 35. 
in erstaunlicher, dem Verfasser wohl selbst nicht bewusster Weise die anderen Pole ignoriert. Dies ist ein grundlegender Widerspruch, der durch die Wahl indianischer beziehungsweise indigener Namen eher noch betont wird.

Die zarte romantische Liebesgeschichte, die sich zwischen diesen drei Personen entspinnt, ist nicht etwa - wie Sie vermuten könnten - eine Dreiecksgeschichte, bei der dann notwendig gemäß der Vorstellungen des Jahrhunderts eine der drei Inseln den kürzeren hätte ziehen müssen. Es handelt sich dabei vielmehr um die freundschaftliche Beziehung zwischen der Titelfigur Bayoán und seinem wesentlich älteren Freunde Guarionex, in dessen gerade mal fünfzehnjähriges empfindsames Töchterlein sich der junge Puerto-Ricaner mit Einverständnis und Segen des ergrauten Freundes verliebt. Das Problem bei der Sache ist die ständige Bewegung, wenn Sie so wollen die Außenorientierung Bayoáns, welche schon im Titel zum Ausdruck kommt: Bayoán ist ein Pilger, ein Wallfahrer, der freilich ein Ziel ansteuert, das er nicht finden kann. Denn er sucht und versucht, eine Heimat $\mathrm{zu}$ finden, eine Heimat zu gründen. Auch dieser Roman ist also eine „novela fundacional“, wie wir mit Doris Sommer sagen könnten: ${ }^{16}$ Auch er gehorcht jenen Grundlagen des lateinamerikanischen Romans des 19. Jahrhunderts, mittels verschiedenartiger Allegoresen die Möglichkeiten durchzuspielen, den Nationenbildungsprozess der jeweiligen Nation oder Insel voranzutreiben und $\mathrm{zu}$ beschleunigen.

Die bevorzugte Schreibform, das architextuelle Modell also, ist in La Peregrinación de Bayoán das Reisetagebuch, das symbolträchtig mit einem zwölften Oktober einsetzt, jenem Tag, an dem eben diese Inseln und Amerika insgesamt in das Gesichtsfeld des Christoph Kolumbus, vor allem aber in den Bannkreis und den Expansionsdurst europäischer Geschichte eintraten. Es ist, als ob mit diesem traumatischen Datum die Geschichte überhaupt erst begänne. Bald freilich merkt das Lesepublikum, dass es sich bei diesen Notizen weniger um ein Bordbuch handelt, also um einen „Diario de a bordo“ in Fortführung des Kolumbus, als um ein „Journal intime“, welches der jugendliche Held führt, um sich über seine Gefühle und Gedanken Klarheit zu verschaffen. Es sind weniger die Koordinaten einer äußeren, als die Stationen einer inneren Reise, die im Bordbuch einer romantischen Seele ihren literarischen Niederschlag finden. Dabei lässt sich in diesem romanesken Text kaum die Tendenz zu einem Bildungsroman nachweisen - zu festgelegt ist schon von Beginn an die tragische Rolle des Titelhelden, dessen unglückliche Konstituiertheit im privaten Bereich ebenso offengelegt erscheint wie jene politische Problematik, an welcher er sein eigenes Glück und

16 Vgl. Sommer, Doris: Foundational Fictions. The National Romances of Latin America. Berkeley: University of California Press 1991. 
das der jungen Marién abarbeiten wird: Einmal mehr ist das romantische Scheitern also vorprogrammiert.

Doch noch hat Bayoán die junge Kubanerin nicht getroffen. Er verfügt über zwar beschränkte, aber dennoch für einen längeren Aufenthalt in Spanien ausreichende Geldmittel, die es ihm sogar erlauben würden, eine umfassende Reise quer durch den Südteil seines Kontinents anzutreten, um von dort aus über Mexiko die Reise nach Europa (sprich Spanien) unternehmen zu können. Ein solcher Reiseweg über die karibische Küste des südamerikanischen Subkontinents bis hinunter nach Peru und zurück über Mexiko ist zum damaligen Zeitpunkt jedem Hispanoamerikaner bekannt: Es handelt sich mehr oder weniger um die Reiseroute Alexander von Humboldts und Aimé Bonplands bei ihrer Forschungsreise von 1799 bis 1804 durch die Tropen Amerikas. Es ist immer wieder erstaunlich und verblüffend, wie präsent diese Reise im lateinamerikanischen Roman ist bis hinein in unsere Gegenwart, vor allem aber natürlich im 19. Jahrhundert! Wir haben bereits verschiedene Beispiele für diese Präsenz in unserer Vorlesung gesehen, könnten aber auch auf Jorge Isaacs Roman María hinweisen, den ich in einer anderen Vorlesung behandelt habe und in dem sich die romantische Liebe mit dem Thema der Krankheit verquickt. ${ }^{17}$

Die Reise quer durch die Karibik, an einem zwölften Oktober begonnen, wird Bayoán von seinem Borinquen - der bis heute geläufige Name für Puerto Rico entlang der Küsten des indianischen Haití oder der Isla Española, also der Dominikanischen Republik und Haitis, entlang der Südküste Kubas quer durch die Jardines de la Reina vor der kubanischen Westküste nach La Habana führen. Nach einem Aufenthalt, auf den ich zurückkomme, geht es nach Guanahaní, jenen mythischen Ort, an dem Christoph Kolumbus alias Cristóbal Colón erstmals den amerikanischen Teil unseres Planeten berührte. Den Kennern unter Ihnen wird gleich aufgefallen sein: Dies ist in zentralen Teilen die Reiseroute des Kolumbus während dessen erster Reise, wenn auch teilweise in umgekehrter Richtung, eine Route, deren historischer Hintergrund dem puerto-ricanischen Intellektuellen Bayoán sehr wohl bewusst ist. Dessen Reise ist auf einer ersten Ebene sicherlich die Vergewisserung bezüglich des eigenen Raumes, der in des Wortes ursprünglicher Bedeutung er-fahren, als persönlich erlebter Raum ausgespannt wird. So macht auch der Verzicht Bayoáns auf eine Fortsetzung der Reise nach Süden, hin zum amerikanischen Kontinent Sinn: Er beschränkt sich auf die Area des karibischen Raumes, dessen geokulturelle Einheit beschworen wird.

Ein Grundmotiv des Romans klingt bereits in dessen lyrischem Incipit an: die Sehnsucht nach der Heimat, dem eigenen Raum und dem nur dort verankerten

17 Vgl. hierzu den zweiten Band der Reihe „Aula“, also Ette, Ottmar: LiebeLesen, S. 496-528. 
Glück, sowie die Notwendigkeit, ja Zwanghaftigkeit aufzubrechen und die kollektiven Ziele woanders, in der Alten Welt zu erreichen. Die Tagebucheintragungen unseres Helden vermitteln mehrfach die äußeren klimatischen und die inneren seelischen Bewegungen: Der Sturm, der Hurrikane, der sich auf See erhebt, ist der „tempestad de mi alma“, ${ }^{18}$ dem „Stürmischen meiner Seele“ parallelgestellt, eine Korrespondenz zwischen Mensch und Natur, die wir schon mehrfach als Korrespondenz-Natur im Roman der Romantik bemerkt hatten.

Die Reise quer durch die Karibik kann nicht erfolgen, ohne dass der Protagonist beim Auftauchen der einzelnen Inseln nicht das Geburtstrauma jener Inselwelt evozierte: die grausame Eroberung der miteinander in Verbindung stehenden Inseln durch die spanischen Konquistadoren. ${ }^{19}$ Die Betrachtung der karibischen Landschaften wird ständig durch einen historischen Rückblick gestört oder doch massiv unterbrochen: Stets bringt sich dieser geschichtliche Epochenwandel heftig in Erinnerung. Es handelt sich um eine hochgradig historisch aufgeladene Landschaft, die voller Konflikte steckt. Die Eroberung im Zuge der Conquista, der Genozid an den indigenen Bevölkerungen, die Zwangsdeportation afrikanischer Sklaven und die Jagd auf diese, wenn sie in die Berge zu fliehen vermochten: All dies sind historische Konfliktlagen, welche noch durch die andauernde spanische Kolonialherrschaft traumatisch verstärkt werden. Eine Fußnote von 1873 macht der Leserschaft der zweiten Ausgabe darüber hinaus klar, dass Santo Domingo damals wieder unter spanische Herrschaft gekommen war; eine neuerliche koloniale Abhängigkeit, die bis 1866 andauern sollte, bevor es dem Ostteil der Insel dann endgültig gelang, als Dominikanische Republik politisch unabhängig $\mathrm{zu}$ werden. Stationen einer kolonialen Geschichte werden erkennbar, welche gleichsam das Sich-Durchpausen der Tatsache zeigen, dass die Karibik als Zone verdichtetster Globalisierung in den beiden ersten Phasen beschleunigter Globalisierung eine zentrale Rolle gespielt hatte, welche sich nochmals in der kurz bevorstehenden dritten Phase und dem expansiven Ausgreifen der USA wiederholen sollte.

Ein grundlegender, für die Zeit der Romantik - wie wir sahen - aber charakteristischer Widerspruch besteht in der Tatsache, dass die Conquista zwar verflucht, die Entdeckung des Kolumbus aber gefeiert und begrüßt wird wie in Galváns Enriquillo. Kein Wunder, ist doch - wie wir ebenfalls schon sahen - das kulturelle Konzept des Romans ganz an jener abendländischen Kultur ausgerichtet, als deren positiver Träger der Genuese verstanden wird: Er brachte die abendländische Zivilisation, jenen christlichen Glauben, für den Bartolomé de Las

18 Hostos, Eugenio María de: La Peregrinación de Bayoán, S. 38.

19 Ebda., S. 39. 
Casas steht, er brachte die spanische Sprache, in welcher der Roman selbst verfasst ist. Seit dem 18. Jahrhundert war Christoph Kolumbus zunehmend als Philosoph und im Anschluss rezeptionsgeschichtlich als Genie gesehen worden. ${ }^{20}$ Und an diese Vorstellungen knüpft Bayoán unverkennbar an, wenn er den sogenannten ,Entdecker der Neuen Welt‘ als ein Genie feiert, das zugleich habe leiden müssen aufgrund jener historischen Aufgabe, die ihm von einer quasi göttlichen Instanz anvertraut worden war. Es handelt sich um jene Aufgabe, die schon in seinem Namen Cristóbal, Christo-phorus, Christum ferens anklingt, nämlich als ein Glaubensbringer des Christentums in einer Welt zu fungieren, die dem Christentum bis dahin noch unzugänglich gewesen war. Genie und Märtyrer: Wir sehen ein weiteres Mal, wie präsent die Gestalt des Kolumbus im Roman der spanischsprachigen Karibik ist, wo sie gleichsam den Beginn aller Geschichte und aller Geschichten signalisiert.

Eine gewisse Gerechtigkeit der politischen Geschichte sei darin zu erblicken, dass Spanien für seine früheren Fehler, für die Grausamkeiten seiner Eroberung und Ausplünderung in der Gegenwart schwer büßen müsse. Damit kommt ein Prinzip fast göttlicher Gerechtigkeit in die Geschichte, die deutlich eine tröstende Funktion erhält: das Prinzip einer ausgleichenden göttlichen Justiz. Ähnlich verhält es sich auch mit der Komponente der Zukunft, werde doch Spanien bald schon seine Blindheit - eine häufig wiederkehrende Metapher - ablegen und erkennen müssen, dass Amerika der Kontinent und die Kultur der Zukunft sein werde. ${ }^{21}$ Damit wird erstmals die Vorstellung von Amerika als Zukunfts-Kontinent in den Roman eingeführt; eine Vorstellung, die sich bereits in den nach Amerika projizierten europäischen Utopien angekündigt hatte, bewusst und philosophisch-weltgeschichtlich aber dann von Hegel auf den Punkt gebracht worden war. Wir hatten außerdem gesehen, welch wichtige Rolle dabei Alexis de Tocqueville und seinen Überlegungen zur Demokratie in den Vereinigten Staaten von Amerika zugefallen war.

Gewiss war Hegels Rede von Amerika als Kontinent der Zukunft weniger auf Südamerika und schon gar nicht auf die Karibik als Area gemünzt. Doch dieser Aspekt war Hostos keineswegs wichtig, wollte er doch wie auch andere lateinamerikanische Intellektuelle den Meridian künftiger Weltgeschichte von Europa nach Amerika verrückt wissen. Die Rede vom Kontinent der Zukunft schien im Übrigen auch im 20. Jahrhundert nicht ausrottbar zu sein, sahen doch insbeson-

20 Vgl. zur Rezeptionsgeschichte Heydenreich, Titus (Hg.): Columbus zwischen zwei Welten. Historische und literarische Wertungen aus fünf Jahrhunderten. 2 Bände. Frankfurt am Main: Vervuert Verlag 1992.

21 Hostos, Eugenio María de: La Peregrinación de Bayoán, S. 42. 
dere mexikanische Schriftsteller und Intellektuelle wie Alfonso Reyes oder José Vasconcelos - wie ich in einer anderen Vorlesung gezeigt habe ${ }^{22}$ - die Zukunft des lateinischen Amerika in rosigen Farben. Erst die achtziger Jahre des 20. Jahrhunderts brachten eine so tiefgreifende Ernüchterung, dass bis in unsere Zeit kein ernstzunehmender Intellektueller und keine seriöse Essayistin aus Lateinamerika vom südlichen Amerika als einem Kontinent der Zukunft sprechen konnte.

Auszurotten ist diese Vorstellung freilich nicht und feiert im politischen Diskurs lateinamerikanischer Populisten, die in den Untergang ihrer Länder steuern, fröhliche Urstände. Auch im letzten Drittel des 19. Jahrhunderts verschwand dieses politische Diskurselement keineswegs, als jener optimistische, ja jenseits aller Fakten euphorisierende amerikanistische Diskurs von einem pessimistischen überlagert wurde, in welchem aufgrund der historischen Erfahrungen vor allem vom ,kranken Kontinent‘ die Rede war. Doch kehren wir zu unserem puerto-ricanischen Roman zurück; denn bei Bayoán scheint der geschichtsphilosophische Optimismus noch weitgehend ungebrochen - wenn auch nicht der an einer sozioökonomischen Modernisierung ausgerichtete Fortschrittsglaube.

Die Reise durch das „Meer des Kolumbus“23 führt zu einer starken geistigen Erregung angesichts dessen, was die Inselwelt vor der Eroberung durch die Spanier gewesen war und angesichts dessen, was diese Inselwelt heute noch sei: Deren ursprüngliche Bewohner seien gänzlich verschwunden. Die „noble raza“, welche die Spanier so wohlwollend aufgenommen hatte, sei nunmehr ausgelöscht. ${ }^{24}$ An dieser Stelle darf natürlich ein Verweis auf die Gegend von Jaragua nicht fehlen und auf das traurige Schicksal der unglücklichen Anacaona, der - wie wir sahen einige Jahre später Manuel de Jesús Galván in seinem Enriquillo huldigen sollte. Auch Bartolomé de Las Casas wird als Schutzpatron der indigenen Bevölkerung angerufen: Wo sind die von Dir geschützten Indianer heute? Sie sehen: Es sind immer wieder dieselben geschichtlichen Erfahrungen, immer wieder dieselben intertextuellen Bezugstexte, welche bei den karibischen Autoren im Vordergrund ihrer romanesken Schöpfungen stehen!

Die spanischsprachige Karibik erweist sich auf dieser literarischen Ebene als wesentlich homogener als aus einer geokulturellen Sicht erwartet und zeigt sich folgerichtig als eine ebenso komplexe wie kompakte Area, in welcher die Auslöschung der indigenen Bevölkerung wie die Versklavung der hierher deportierten schwarzen Arbeitskräfte die Geburtstraumata einer auf Extraktionswirtschaft und

22 Vgl. hierzu die Vorlesung von Ette, Ottmar: Von den historischen Avantgarden bis nach der Postmoderne, S. 196-227

23 Hostos, Eugenio María de: La Peregrinación de Bayoán, S. 49.

24 Ebda., S. 52. 
Plantagenökonomie aufbauenden kolonialen Gesellschaftsordnung waren. Eine Meditation über die göttliche Vorsehung darf natürlich auch hier nicht fehlen, deren Hand der Protagonist und Ich-Erzähler im unterschiedlichen Schicksal der verschiedenen Völker zu erkennen glaubt. Da fragt sich nur, welche Providenz denn das Geschick der untergegangenen Indianer so erbarmungslos geregelt hatte - oder traf für sie die christliche und auf Heil und Erlösung zielende Vorsehung nicht zu?

Bayoán sinnt im Roman darüber nach, welchen ,sarkastischen Fortschritt“ die Europäer diesen Inseln gebracht hätten. ${ }^{25}$ Die Wohltaten der europäischen Kultur erweisen sich bei historischer Beobachtung als bestenfalls oberflächlich und nur scheinbar als Wohltaten. Wir konstatieren: Zivilisationskritische Elemente sind im Romandiskurs durchaus vorhanden, sind aber eher rousseauistischer Provenienz und nicht mit einer grundsätzlichen Öffnung gegenüber anderen Kulturen verbunden. Dies zeigt sich auch bei der durchgängig negativen Einschätzung der Städte gegenüber dem stets idyllisch-exotisierend angerufenen Landleben in den Tropen. Der an Rousseau angelehnte, im Grunde aber rousseauistische Gegensatz zwischen Freude und Sittenstrenge der Landbevölkerung zu der allen Lastern ergebenen Stadtbevölkerung wird freilich innerhalb des karibisch-kolonialspanischen Kontexts durch eine Tatsache verschärft und verändert: Die Städte der Karibik sind zugleich die Zentren kolonialspanischer Verwaltung und Ausplünderung, so dass hier also die Wurzel dessen liegt, was der Ich-Erzähler durch seine Pilgerfahrt nach Spanien überwinden möchte. Denn sein Ziel ist die Abschaffung der Tyrannei und Abhängigkeit von der spanischen Metropole, von Madrid, dem Inbegriff allen kolonialen Übels. Der Besuch des Protagonisten in Havanna, dem Sitz der spanischen Capitanía General über die Antillen, ist in diesem Zusammenhang nichts anderes als das Vorspiel zum metropolitanen Madrid. Als kolonialspanisches Verwaltungszentrum ist La Habana nicht anders als die europäischen Städte eine Stätte der Verderbnis, die mit denselben ,apariencias del progreso“, demselben Anschein von Fortschritt versehen ist. ${ }^{26}$

Nach der Abreise von Havanna gerät das Schiff wieder in einen Sturm, ein Naturereignis mit Folgen, wird doch so erst jener Aufenthalt an Land in Kuba erforderlich, bei welchem der junge Bayoán die noch jüngere Marién kennenlernen wird. Am Anfang dieser fatalen Liebesbeziehung also steht die Providenz in Gestalt eines Naturereignisses. Es regnet wieder einmal im hispanoamerikanischen Roman, und diesmal sollen Sie beim Prasseln der sintflutartigen Regentropfen dabei sein: „Die Katarakte des Himmels öffneten sich und es regnete, wie

25 Ebda., S. 60.

26 Ebda., S. 62. 
es in dieser Welt zu regnen pflegt, in der alles außer dem menschlichen Geist groß ist.“ Und weiter: „Der Regen ist das Weinen des Himmels: In seinen Erregtheiten eines in die Erde Verliebten endet alles wie die Wut des Mannes gegen seine Liebhaberin: mit dicken Tränen. “27

Sie verstehen jetzt vielleicht besser, warum ich mich als junger Studierender vor meiner ersten Reise nach Lateinamerika auf einen Regenfall in den Tropen freute, ja mich unbedingt nach einem tropischen Regen sehnte, hatte ich es doch im lateinamerikanischen Roman bereits so häufig regnen sehen. Der sintflutartige, gewaltige und alles mit sich fortreißende Regen steht für die Gewalt und Größe der amerikanischen Welt, wird aber sofort in den Romanverlauf wieder eingebunden, mit der kommenden Liebesthematik verknüpft und perspektivisch auf die Flüssigkeit der Tränen hin geöffnet, die den lacrimogenen Teil des Romans kräftig ausspülen werden. Es regnet im lateinamerikanischen Roman kaum stärker als das Weinen und Schluchzen der Liebenden, die auf einem Kontinent, wo alles groß ist, sicherlich ebenfalls ein wenig mehr Tränen vergießen als anderswo.

Der Besuch im Hause seines Freundes Guarionex führt den Ich-Erzähler durch eine karibische Landschaft mit Sümpfen, Zuckerrohrfeldern und - geradezu als typisches Landschaftselement - schwarzen Sklaven, die von Guarionex natürlich zuvorkommend behandelt und von Zeit zu Zeit gesegnet werden. Er führt Bayoán jedoch vor allem zu einer Erscheinung: der Tochter des Hauses, der schönen fünfzehnjährigen Marién. Nicht umsonst ist der Name gleichzeitig kubanisch-indianisch und christlich-marienhaft: Andächtig stehen wir vor einer weißen kubanischen Jungfrau, deren unkörperliche Erscheinung schon darin zum Ausdruck kommt, dass ihre physische Gestalt zunächst einmal nur evoziert, nicht aber hautnah beschrieben wird. Sie ist keine irdische Erscheinung, sondern im Grunde ein Engel. Die „adolescente“ ist nicht notwendigerweise schön - als physisch schön wird sie erst am Ende ihres kurzen Lebens, fast schon im Sterben liegend beschrieben -, aber lichtvoll, ist „luminosa“ und besitzt das sanfte Leuchten des Himmels. ${ }^{28}$ Kein Zweifel: Marién ist marienhaft himmlisch. Doch als Verkörperung unerfüllbarer romantischer Liebe führt auch ihr Weg nur über ihre schöne Leiche. ${ }^{29}$

27 Ebda., S. 65: „Se rompieron las cataratas del cielo, y llovió, como llueve en este mundo en el que todo es grande, si exceptúo el espíritu del hombre. // La lluvia es el llanto del cielo: en sus enojos de enamorado con la tierra, concluye como la cólera del hombre con su amada: con lágrimas copiosas.“

28 Ebda., S. 73.

29 Vgl. Bronfen, Elisabeth: Nur über ihre Leiche. Tod, Weiblichkeit und Ästhetik. München: Deutscher Taschenbuch Verlag 1994; sowie (dies., Hg.): Die schöne Leiche. Weibliche Todesbilder in der Moderne. Wien: Goldmann 1992. 
Ein einziges Mal hat Bayoán Marién gesehen, und schon ist die Welt voll von ihr. Das ist im Umkehrschluss eine Formel romantischer Liebe, auf die wir schon mehrfach stießen und deren französischen Urheber Alphonse de Lamartine wir bald endlich kennenlernen werden. Doch auch Marién hat gesehen: Ihre Blicke sprechen eine deutliche Sprache, blickt doch aus beider Augen die Seele heraus. Bei beiden Liebenden liegt - wenn Sie mir den Ausdruck gestatten - die Seele blank vor den Augen der Lesenden.

Die Seelen sprechen ohne zu sprechen zueinander, nachdem ihre AugenBlicke sich trafen. Bis zum Ende des Romans wird es sich um eine vorwiegend okulare Beziehung handeln: Das Auge ist der menschliche Fern-Sinn und hält auf Distanz, ist zugleich aber auch jener Sinn, der die „concupiscentia oculorum“ erzeugt. Der Ich-Erzähler ist im wahrsten Sinne des Wortes hin- und hergerissen zwischen seinem Herzen und seiner Vernunft. Welche Seite wird den Sieg davontragen?

Wir sollten einmal in diese Fragmente eines Diskurses der romantischen Liebe hineinhören: Es beginnt mit der radikalen Einsamkeit des Ichs, wie stets im abendländischen Diskurs der Liebe. ${ }^{30}$ Es handelt sich im Übrigen - wie an vielen anderen Stellen des lyrischen Diskurses im Roman - um eine rhythmisierte Prosa, der man anmerkt, dass Hostos auch ein ausgezeichneter Lyriker war:

Ich habe all jene, die mich umgaben, unglücklich gemacht, und mich selbst habe ich dabei ebenso unglücklich gemacht.

Meine unerbittliche Vernunft verlässt mich nicht, und um mich nicht eines Tages für einen Fehltritt zu schämen, verweigert sie mir das Glück, das ich von ihr fordere. Auf Dein flehen hin höre, was sie antwortet, mein Herz.

„Du bist dazu verurteilt, nicht zu lieben: Wenn Du liebst, machst Du unglücklich: Und wenn Du nicht liebst, auch: Aber wenn du liebend Deiner Liebe widerstehst und Deiner Pflicht nachkommst, Dich zu rufen, so verspreche ich Dir eines Tages das strahlendste Licht: Deine Pflicht ruft Dich weit weg von hier: Gehorche: Wenn Du gehst und sie Dich lieben, so opferst Du heute ...: Die Zeit heilt: Wenn Du liebst und Deine Pflicht vergisst, so erinnere Dich an Dein Gewissen!“

Und inzwischen liebe ich, ich sehe nicht, die ich liebe, sage nicht, wie sehr ich liebe, beraube mich des Lichts: Ich will bleiben und sie stoßen mich vorwärts; ich will aufbrechen, und sie rufen mich!

Und die Liebe ist der Himmel ...!, sagte ich mir gestern.

Oh Vernunft, oh Vernunft, verflucht seist Du! ${ }^{31}$

30 Vgl. hierzu Barthes, Roland: Fragments d'un discours amoureux. Paris: Seuil 1977.

31 Hostos, Eugenio María de: La Peregrinación de Bayoán, S. 78. 
Eine psychische Komplexität gibt es in dieser Passage kaum, sondern eher - spieltechnisch gesprochen - eine psychische Zwickmühle, in der sich der Liebende befindet. Auf der einen Seite steht die Vernunft, auf der anderen das Herz; auf der einen Seite die Pflicht, auf der anderen die Liebe, welche ihr Objekt wie ihr Subjekt unglücklich macht. Da hilft alles Verfluchen der Vernunft nichts: Zwei Seelen sind, ach, in meiner Brust! Die romantische Topik des Liebesdiskurses wird hier in einer Art innerem Dialog vorgeführt, wobei sich im Spanischen „corazón“ auf „razón“ bekanntlich reimt.

Die psychosoziale Konstellation ist vergleichbar mit jener, die sich etwa in dem 1869 entstandenen Theaterstück Abdala des jungen José Martí zeigt: Dort ist der Held ebenfalls zwischen seiner Pflicht gegenüber dem Vaterland und der Liebe - allerdings der Mutterliebe - hin- und hergerissen, entscheidet sich dann aber heldenhaft für die Pflicht. Auch Bayoán muss sich für letztere entscheiden und sein Vaterland erretten vor der kolonialspanischen Tyrannei. Und doch ist er - wie ihm die Vernunft schon sagte - in einer Zwickmühle gefangen: Er wird unglücklich machen und selbst unglücklich sein. Die unentrinnbare Fatalität ist angedeutet und skizziert, aus der es kein Entrinnen gibt, und die der Roman in seinem weiteren Verlauf bis zur Neige auskostet.

Bayoán weiß: „Mi deber es partir, partir“32 - Seine Pflicht ist es, aufzubrechen, aufzubrechen. Der Pilger muss sich wieder auf den Weg begeben, um Borinquen, der gleichfalls unglücklichen Heimatinsel, ebenfalls zu Glück zu verhelfen und die Entstehung eines unabhängigen Vaterlandes zu ermöglichen. Für die Liebenden, so ließe sich auf Ebene einer ideologischen Lektüre sagen, ist in den kolonialspanischen Ländern kein Platz im Sinne einer Fusion, kein Platz für ein glückliches Leben zu zweit. So werden die beiden ihr gemeinsames Leiden aneinander und am anderen auch außerhalb der Welt der Karibik erfahren: eine Außerhalbbefindlichkeit, die letztlich politisch motiviert und vom romantischen Diskurs hispanoamerikanisch integriert wird. Es ist die Zerrissenheit des romantischen Helden zwischen seiner Liebe zum Vaterland und seiner Liebe zur geliebten Frau.

Die Frage freilich bleibt, ob man Europa davon überzeugen könne, dass Amerika der Ort einer Zivilisation der Zukunft ist; ${ }^{33}$ einer Zivilisation freilich, die nicht wie später bei José Vasconcelos auf einer kulturellen Vermischung, einem „mestizaje“, sondern zumindest im Roman auf einer konsequenteren Verwirklichung und Durchsetzung abendländischer Tugenden und Werte beruht. Für dieses Ziel kämpft Bayoán - und ein Traumbild macht der Leserschaft klar, dass

32 Ebda., S. 89.

33 Ebda. 
die Freiheit des Volkes mit der Selbstaufopferung des romantischen Helden erkauft wird; eines großen Mannes, der den Kelch, der ihm gereicht wird, in vollem Bewusstsein austrinkt. ${ }^{34}$ Die Erde erscheint als ein Ort, an dem kein Glück möglich ist - höchstens das oberflächliche Glück der Dummen und Indifferenten. ${ }^{35}$ Denn das Glück findet sich nur außerhalb der vom Menschen bewohnbaren Welt oder, um es mit dem Titel eines Prosagedichts von Charles Baudelaire zu sagen, Anywhere Out Of The World.

Die Problematik der Entscheidung Bayoáns zugunsten von Pilgerschaft und Pflicht liegt darin, dass er - wie Mariéns Mutter ihm bereits deutlich vor Augen führt - seine jugendliche Geliebte, die wie alle romantischen Heldinnen über eine nur schwache Konstitution verfügt, mit dem Befolgen seiner Pflicht zum Tode verurteilt. Da er kein Mitleid mit dem Glück eines Engels gehabt habe, werde er ein Leben lang unglücklich sein müssen. ${ }^{36}$ Eine Stimme habe ihr gesagt, dass Marién sterben werde, er aber weiterleben müsse, um als Märtyrer, als Blutzeuge zu leiden. An diesem Leiden führt für ihn kein Weg vorbei.

Denn Bayoán zieht einer glücklichen Gegenwart die unglückliche Zukunft vor. Er ist, so dürfen wir aus dem Vorwort schließen, die Verkörperung des logischen Menschen; und so nimmt auch die Logik des Romans unabwendbar ihren Lauf. Marién ist Vertreterin einer romantischen Liebeskonzeption und ihres Absolutheitsanspruches, Bayoán hingegen repräsentiert einen etwas anderen Standpunkt, da für ihn die Liebe Vorausschau des Künftigen sei, er also im Glück des Heutigen das Unglück des Künftigen erblickt. Zugleich ist er das Prinzip des Männlichen, Bewegenden, Initiativen, während Marién nur die Rolle der Leidenden, Ausgelieferten, Bedrohten und Passiven bleibt. Hostos' Roman entspricht damit den gängigen genderspezifischen Mustern seiner Zeit. Zwischen Pilgerschaft und Liebe kann sich Bayoán höchstens für die Liebe während der Pilgerschaft entscheiden. Da hilft es auch nichts, dass die Liebe als eine das ganze Universum erfüllende Kraft erscheint, die Natur wie Mensch bewegt und am Leben erhält. ${ }^{37}$ Die Würfel sind gefallen: Mariéns, aber auch Bayoáns Schicksal ist entschieden!

Die Bank im Freien, auf der sich die Liebenden den ersten Kuss gaben, die Hand der Toten, die den letzten Kuss des Liebenden empfängt - die aus JeanJacques Rousseaus Briefroman Julie ou la Nouvelle Héloïse bekannten Elemente sind ebenso nachzuzeichnen wie jene, die einmal mehr auf den grundlegenden Einfluss von Chateaubriands Atala verweisen. Auch Marién träumt von jener

34 Ebda., S. 92.

35 Ebda., S. 97.

36 Ebda., S. 105.

37 Ebda., S. 119. 
„choza“, jener Hütte, wo sie mit ihrem Geliebten ein einfaches, aber glückliches Leben führen werde - ein Traum, den auch die Romane von Gertrudis Gómez de Avellaneda und Manuel de Jesús Galván träumten und der auch in Jorge Isaacs María wieder auftaucht. Die Kontinuität der präromantischen wie der romantischen Handlungselemente ist beeindruckend, wird aber durch die spezifisch lateinamerikanische Ausrichtung an einem schwierigen, wenn nicht gescheiterten Nationenbildungsprozess in eine Richtung getrieben, die den europäischen Romanen weitgehend unbekannt war. Dabei sind die modifizierenden Textelemente letztlich bestimmend.

Der Abschied der beiden hoffnungslos Liebenden ist unaufschiebbar und wird nur bewältigt aufgrund eines Sinnenverlusts, der Bayoán erst an Bord wieder zu Verstand kommen lässt. Das Schiff ist dabei Symbol seines eigenen Lebens: „buques sin rumbo, pájaros sin nido“, ein Schiff ohne Ziel und Vögel ohne Nest. Dies sind die ziel- und heimatlosen Menschen, die mit ihren Sorgen den Roman bevölkern, wobei das romantische Ich zugleich erkennt, dass es in seiner Absolutheit doch nicht losgelöst von anderen sein kann. Das Ich muss in einer Atmosphäre leben, die vom intellektuellen Leben seiner Zeit geprägt wird: ${ }^{38}$ Man ist verdammt dazu, in derselben Epoche in derselben Atmosphäre zu leben und kann sich die bestimmenden Strukturen seiner Gesellschaft nicht aussuchen.

Was in mir ist, so der Protagonist, kommt von den Anderen - hier scheint bereits eine Idee Friedrich Nietzsches auf, der danach fragte, wer und was in mir spricht, wer und was in mir denkt. Zugleich scheint der romantische Diskurs umzuschlagen in Richtung auf das, was man das Erkennen der wissenssoziologischen beziehungsweise soziologisch-diskursiven Dimension des Lebens und Schreibens nennen könnte. Doch kehrt der Protagonist rasch wieder zur dominanten Metaphorik der Romantik zurück. Die Menschen bilden in ihrer Gesamtheit jene Ebene, jene Fläche, aus der sich heraus der Chimborazo des großen Menschen - fast hätte ich gesagt: des Über-Menschen - erhebt:

Ich sehe eine fantastische Welt, die der Erde gleicht: In den Ebenen, in den fruchtbaren Auen, an den Küsten, in allem, was sich ähnelt, ist alles gleich und auf derselben Ebene, in ruhiger Atmosphäre: in den Bergen Nebelschwaden; in den Anden ewige, dunkle Wolken. Die Menschen sind die Ebenen, die Strände, das, was sich auf einer Ebene befindet; der Mensch, der sich erhebt, ist der Chimborazo, der innerlich in ewigem Feuer brennt, äußerlich aber von dauerhaften Wolken verhüllt ist.

„Meditiere über diese Allegorie ...!“39

38 Ebda., S. 136.

39 Ebda., S. 138. 
Lassen Sie uns also über diese Allegorie meditieren, sie ist es wert! Denn nicht umsonst wird in diesen Wendungen der Chimborazo gewählt, der in Lateinamerika noch immer als höchster Berg der Welt galt. Für den lateinamerikanischen Zeitgenossen verkörpert dieser Berg darüber hinaus nicht nur den vergeblichen, aber symbolträchtigen Versuch seiner Erstbesteigung durch Alexander von Humboldt, ${ }^{40}$ sondern auch die düstere Meditation, die der „Libertador“ Simón Bolivar hier bei seinem Besteigungsversuch anstellte. ${ }^{41}$ Der Chimborazo ist damit zugleich auch ein Ort der Verständigung über das Amerikanische und die InWert-Setzung seiner Erhabenheit, des Amerikanisch-Sublimen. Vor allem aber wird in der angeführten Passage eine Landschaft der Theorie ${ }^{42}$ ausgespannt, in welcher die vertikale Dimension, die Größe und Höhe in Szene gesetzt wird und die Fähigkeit zu innerer Bewegtheit, insofern im Inneren des Andenvulkans und von außen nicht sichtbar ein ewiges Feuer lodert, das für die ständige Umwälzung und Umgestaltung aller Dinge steht. Der Vulkanriese ragt aus seiner Umgebung hervor wie Inseln aus dem sie umgebenden Wasser.

Gleichzeitig ist die Allegorie von Gebirge und Tal, Gipfel und Ebene eine topische Metaphorik, in der die Romantik das herausragende Genie zu fassen pflegte. Es ist diese Bildsprache, die José Martí wenige Jahre später verwandeln wird zu einem Manifest nicht mehr des Individuellen, sondern des Kollektiven. In einem Text von Juni 1875 für die Revista Universal deutet sich bereits an, dass Martí die Veränderungen in Politik, Gesellschaft und Ästhetik wahrgenommen hat und erkennt, dass die Metaphorik von Berg und Ebene nicht mehr die gesellschaftliche Situation wiederzugeben in der Lage ist. Sehen wir uns diese Passagen, mit denen wir mit dem Vordenker Martí in Lateinamerika aus der Romantik deutlich heraustreten, etwas genauer an:

Das Menschengeschlecht verfügt über Berge und Ebenen, und so sprechen die Berge von der Erde mit den Höhen der Himmel, wie die Genies unter den Menschen mit den Hoheiten und Exzellenzen des Geistes reden. [...] Doch scheint es, dass so, wie die Hand des Menschen die Erhebungen der Erde zerstört, auch ich weiß nicht welch verborgene Hand sich darauf ver-

40 Vgl. hierzu Humboldt, Alexander von: Ueber einen Versuch den Gipfel des Chimborazo zu ersteigen. Mit dem vollständigen Text des Tagebuches „Reise zum Chimborazo“. Herausgegeben und mit einem Essay versehen von Oliver Lubrich und Ottmar Ette. Frankfurt am Main: Eichborn Verlag (Eichborn Berlin) 2006.

41 Vgl. zur Meditation des Libertador auf dem Dach der Anden Stackelberg, Jürgen von: Der Mythos vom Befreier. Anmerkungen zu Simón Bolívar. In: Romanistische Zeitschrift für Literaturgeschichte (Heidelberg) 6 (1982), S. 24-44.

42 Diesen Begriff der „Landschaft der Theorie“ habe ich erstmals ausführlicher eingeführt in Ette, Ottmar: Viellogische Philologie. Die Literaturen der Welt und das Beispiel einer transarealen peruanischen Literatur. Berlin: Verlag Walter Frey - edition tranvía 2013. 
steift, dasselbe mit den Höhen des Menschengeschlechts zu tun; - und die Intelligenz macht sich gemein und verbreitet sich über die aufgegebenen Ebenen, und ganz so, wie sich im Gemeinen der Leute eine größere Sinnhaftigkeit in der Beurteilung beobachten lässt, mehr Lebhaftigkeit im Verstehen und in nützlichen Kenntnissen größerer Reichtum, so fehlen oder verbergen sich jene hohen Gipfel des Talents, die zuvor in einem einzigen Gehirn die Schicksale wie die Zukunft einer ganzen Nation enthielten.

Alles verbreitet sich mit den Samen von Gerechtigkeit und Gleichheit; eine gute Tochter der Freiheit ist diese Verallgemeinerung und Häufigkeit des Talents. ${ }^{43}$

José Martí zog in diesem Text von 1875 kulturtheoretische Konsequenzen aus jenem Unbehagen an der Kultur, das mehrfach im Text des jungen Hostos 1863 anklingt, aber von ihm immer wieder in eine romantische Genieästhetik zurückgebogen wurde. Beide karibische Autoren - und dies ist an sich bereits für die Area charakteristisch - fragen jeweils universalistisch nach einer Gesetzlichkeit, welche für die gesamte Menschengattung Geltung beanspruchen und sich nach den Prämissen einer westlichen, auf Gerechtigkeit, Gleichheit und Freiheit beruhenden Wertesystem ausrichten sollte. Dabei versteht es der junge Martí, seine Landschaft der Theorie mit Blick auf das gesamte Menschengeschlecht dahingehend zu verändern, dass er sich nicht länger an den einsamen Gipfeln ausrichten mag, sondern die allgemeine Erhöhung der Ebenen uneingeschränkt begrüßt.

Die Tragweite dieser Entwicklung lässt sich schwerlich überschätzen: Es stehen fortan nicht mehr die einsamen, schneebedeckten Gipfelhöhen des Genies im Vordergrund, sondern die für ganze Ebenen fruchtbaren Verbreitungen der Prinzipien von Freiheit, Gleichheit und Gerechtigkeit. Sie gelte es fortan zu befördern!

Derselbe José Martí bringt all dies in einem Text von 1882, eben jenem Jahr des Erscheinens von Ismaelillo fast ,Manifest'-artig zum Ausdruck, jenes Gedichtbandes, der als die Ouvertüre des Modernismo gesehen werden darf und in seinen kunstvoll einfachen Versen mit der Romantik definitiv abschließt. Es ist das berühmte Vorwort zum Poema del Niágara des mit ihm befreundeten venezolanischen Lyrikers Juan Antonio Pérez Bonalde, wo es in Überwindung derselben Berg-und-Ebene-Metaphorik prophetisch heißt:

Ein großes Gebirge erscheint als kleiner, ist es von Hügeln umgeben. Und dies ist die Epoche, in welcher die Hügel sich zu den Gebirgen hin aufgipfeln; in welcher die Gipfel sich langsam in Ebenen auflösen; die jener anderen Epoche schon nahe ist, in welcher alle Ebenen Gipfel sein werden. Mit dem Abfallen der Erhebungen steigt das Niveau der Ebenen an, was den Weg über die Erde leichter machen wird. Die individuellen Genies treten weniger hervor, da

43 Martí, José: Asuntos para boletín (1875), in: ders.: Obras Completas. Bd. 6. La Habana: Editorial de Ciencias Sociales 1975, S. 222. 


\begin{abstract}
ihnen die Niedrigkeit der Umgebung fehlt, welche zuvor so sehr ihre Statur bestärkte. [...] Wir wohnen so etwas wie einer Dezentralisierung der Intelligenz bei. Das Schöne ist zum Herrschaftsbereich aller geworden. Die hohe Zahl an guten zweitrangigen Poeten erstaunt ebenso wie der Mangel an herausragenden, solitären Dichtern. Das Genie geht langsam vom Individuellen zum Kollektiven über. Der Mensch verliert zugunsten der Menschen. Die Eigenschaften der Privilegierten lösen sich auf, weiten sich zur Masse aus; was den Privilegierten von niederer Seele nicht gefallen wird, wohl aber denen von keckem und großzügigem Herzen, die wissen, dass es auf Erden, so groß man als Geschöpf auch sein mag, nicht mehr als Gold-Sand gibt und dass alles zur herrlichen Quelle des Goldes zurückkehrt, in welcher sich der Blick des Schöpfers spiegelt. ${ }^{44}$
\end{abstract}

Gänzlich und von Grund auf verändert ist jene Landschaft der Theorie, welche in diesen selbstbewussten Wendungen für den Betrachter, für die Leserin skizziert und ausgespannt wird. Jene Entwicklung hin zu einer Dezentralisierung der Intelligenz, zu einem Übergang von der Betonung des Individuellen hin zur Dominanz des Kollektiven, wird am Beispiel einer Landschaft vorgeführt, in welcher sich nicht nur ein einziger Parameter - etwa die Höhe der Berge -, sondern alle Bezugs-Parameter verändern. In sanften Übergängen, aber mit revolutionärem Inhalt wird die Landschaft der Romantik umgestaltet, welche selbst noch in ihrer Malerei - wie ein Vergleich mit aktuellen Fotografien zeigen kann - die Steilheit ihrer Bergspitzen noch übersteilte, die Höhe ihrer Berge noch überhöhte. Selbst ein so empirisch geschulter und ausgerichteter Kopf wie Alexander von Humboldt übertrieb in seinen Skizzen der andinen Bergriesen die Steilheit der Bergflanken erheblich, um den gewünschten Eindruck beim Publikum zu erzielen.

Mit Martí bricht sich eine neue Ästhetik Bahn, in welcher weitaus weniger der Kontrast zwischen den hohen Höhen und den tiefen Ebenen, sondern die Wechselwirkung zwischen allen Dingen, die sich auf ähnlichem Niveau befinden, im Mittelpunkt der Aufmerksamkeit steht. Dieser Entwurf einer neuen Ästhetik, die sich angesichts einer sozioökonomischen Modernisierung in einer Epoche der Moderne im spanischsprachigen Amerika als „Modernismo“ selbst bezeichnete, wird für die künftigen Jahrzehnte mitentscheidend sein. Wir werden uns mit dieser neuartigen Ästhetik noch näher auseinandersetzen. Doch es ist faszinierend zu sehen, dass diese (nietzscheanisch ${ }^{45}$ gesprochen) ,Umwertung aller Werte‘ am Beispiel einer Landschaft, einer Landschaft der Theorie metaphorisch durchgespielt und figural visualisiert wird.

44 Martí, José: Prólogo al „Poema del Niágara“, in: ders.: OC. Bd. 7, S. 228.

45 Auf Bezüge zwischen dem Modernismo und Friedrich Nietzsche habe ich aufmerksam gemacht in Ette, Ottmar: „Así habló Próspero“. Nietzsche, Rodó y la modernidad filosófica de „Ariel“. In: Cuadernos Hispanoamericanos (Madrid) 528 (junio 1994), S. 48-62. 
Auch für José Martí ist, ebenso wie für den Ich-Erzähler in La Peregrinación de Bayoán, die Stimme des Genies immer rückgebunden an die Stimme Gottes, an die Stimme des Schöpfers, der stets sein Werk betrachtet. „Der Geist ist Gott“ schreibt der Protagonist in sein Tagebuch, just nach der Entwicklung der Allegorie vom Chimborazo. ${ }^{46}$ Die Genies sind auch für Martí nicht gänzlich von der Bildfläche verschwunden. Doch sind sie längst nicht mehr die einsamen Bergspitzen, die sich aus den platten Flächen des Menschengeschlechts heraus erheben. Gerade dadurch, dass Martí noch immer am großen Genie und der Vorstellung von herausragenden Schöpfern festhält, können Sie bereits ermessen, dass in Lateinamerika die Einführung einer neuen Ästhetik keineswegs mit einem radikalen Bruch mit der vorher gültigen und nun zu bekämpfenden einhergeht. Die neue Ästhetik des Modernismo wird auch bestimmte Züge des Romanticismo wo sie ihr genehm erschienen - integrieren, ohne doch ihren Anspruch aufzugeben, eine gänzlich neuartige Ästhetik darzustellen und die Romantik hinter sich gelassen zu haben. So werden im 20. Jahrhundert die historischen Avantgarden in Lateinamerika auch keineswegs den radikalen Bruch mit allem Vorherigen manifestieren, der für die europäischen Avantgarden insgesamt doch charakteristisch war, sondern eigene Wege beschreiten, welche ihre Eigenständigkeit gegenüber den Avantgarden Europas unterstreichen. ${ }^{47}$

Martí hat in der obigen Passage ein zweifellos zentrales romantisches Diskurselement genommen und in seinem Sinne ästhetisch umgearbeitet. Diese Abkehr von der Romantik beinhaltete verschiedenste Facetten: Modernisierung, Disseminierung, Übergang vom Individuellen zum Kollektiven, Verbreitung von Wissen und Wahrheit, von ästhetischer Schönheit und lyrischer Kraft. Hier werden Elemente einer neuen Sichtweise geistiger Aktivität wie ästhetischer Schöpfung sichtbar, die überdies in einer neuen Sprache ihren Ausdruck finden, fernab im Übrigen von paternalistischen Bildern und Metaphern.

Der Übergang vom Individuellen hin zum Kollektiven ist im sozialistischen Kuba bisweilen im Überschwang ideologischer Vorgaben als Ankündigung eines Weges gedeutet worden, der zum sozialistischen Realismus führen würde. Dies ist sicherlich irreführend, hatte Martís modernistische Ästhetik doch nichts mit der eines realsozialistisch gewendeten Realismus gemein. Aber der Ausgleich zwischen den Gipfeln und den Ebenen beinhaltete sehr wohl, dass die ästhetischen Gipfel-Produkte in Lyrik, Malerei oder Musik - um nur diese künstlerischen Bereiche zu nennen - nun der breiten Masse der Bevölkerung zunehmend zugäng-

46 Hostos, Eugenio María de: La Peregrinación de Bayoán, S. 139.

47 Ich habe dies ausführlich dargestellt in Ette, Ottmar: Von den historischen Avantgarden bis nach der Postmoderne, S. 228-234. 
lich wurden. Im Kontext einer sozioökonomischen Modernisierung, wie Lateinamerika sie ab den siebziger Jahren des 19. Jahrhunderts erlebte, wurde es nun möglich (wenn auch nicht selbstverständlich), breiten Bevölkerungsschichten den Weg zu den Künsten zu erschließen und damit tendenziell die Ebenen auf Bergniveau zu bringen.

Beobachten wir die Entwicklung und Bearbeitung dieser Metaphorik zwischen 1863, 1875 und 1882, so stellen wir fest, dass sich in dieser Zeit - dem 1882 erschienenen Enriquillo zum Trotz - zumindest in der spanischsprachigen Karibik, aber auch in anderen Literaturen der hispanoamerikanischen Welt, die Vorzeichen literarischen Schaffens gewandelt haben. Das Ende der Romantik ist gekommen; ein Prozess, den wir anhand der hispanoamerikanischen Lyrik nochmals in seiner ganzen Entwicklung einzufangen versuchen wollen. Vorher aber gilt es, die Analyse unseres Romans von Eugenio María de Hostos abzuschließen und mit der Entwicklung der Literaturen auf dem amerikanischen Festland zu verbinden sowie im Nachgang transatlantisch beziehungsweise transareal zu verorten.

Die bleiche Marién erkrankt gleich nach Abreise ihres Geliebten, die Ärzte raten aus gesundheitlichen Gründen dringend zu einem Aufenthalt in Spanien. Alle treffen sich zufällig in Puerto Rico wieder, von wo aus die Reise dorthin beginnt, die für Marién eine Reise in den Tod, ohne Wiederkehr sein wird. Für Bayoán aber wird diese transatlantische Reise nur eine Station auf seiner langen Pilgerfahrt sein, die in Madrid ihr hehres Ziel - eine Berücksichtigung der legitimen Interessen Puerto Ricos - nicht erreichen kann.

Der Titelheld des puerto-ricanischen Romans befindet sich in der bereits erwähnten Zwickmühle: Vernunft und Gewissen machen es Bayoán unmöglich, seiner Liebe zu Marién höchste Priorität einzuräumen. Erneut erscheint die Vision glücklichen Zusammenlebens unter einfachen Lebensbedingungen. ${ }^{48}$ Bayoáns Konzeption des Glücks ist von Leiden und Schmerz nicht zu trennen; eines Leidens freilich, das nicht allein das individuelle Leiden am Leben ist, sondern sich aus der sozialen Verpflichtung des hervorragenden Menschen gegenüber seinen Mitmenschen, gegenüber der Kollektivität, gegenüber seinem erst noch zu gründenden Vaterland ergibt.

So ist Bayoán, dessen Namensvorfahr an der Unsterblichkeit der Spanier zweifelte, jener, der an der Ewigkeit des spanischen Kolonialismus und der Abhängigkeit der spanischsprachigen Karibik von der spanischen Kolonialmacht zweifelt. Zugleich aber ist er jener andere, der zwischen dem Sozialem und dem Individuellen zutiefst zerrissen ist und seine verlorene Einheit niemals mehr zurück-

48 Hostos, Eugenio María de: La Peregrinación de Bayoán, S. 156. 
gewinnen kann. Das Soziale, das Gesellschaftliche, Nationale und Internationale, ist aber in der Stadt konzentriert und bringt ihm ein sicheres Leiden. Und doch muss er nicht nur die Hauptstadt Puerto Ricos, sondern die spanische Metropole Madrid besuchen; eben jene Stadt, die Inbegriff der Laster, des Verbrechens, der Unmenschlichkeit ist, „metrópoli de los vicios de España“..99 Wie aber soll er sich in dieser Metropole aller Laster der Kolonialmacht verhalten? Vor dem Tribunal der Geschichte werde Spanien gerichtet, aber sicherlich auch begnadigt. ${ }^{50}$ Bayoán selbst jedoch wird von der Geschichte, von der Historie seiner massiv globalisierten Area gewiss noch nicht freigesprochen.

Einen großen Teil des Romans verbringt er an Bord von Schiffen: zunächst auf seiner Reise durch die Karibik, dann während seiner Überfahrt nach Spanien. Auch am Ende wird er erneut ein Schiff besteigen, das ihn nach Amerika zurückbringt. Als er am Horizont verschwindet, ist der Roman zu Ende: Das Meer in all seinen Bewegungen, mit seinen Stürmen, Windstillen, als Trennung und Verbindung ist zentraler Protagonist, eine Hauptfigur des Romans. Kein Wunder also, wenn ihm eine lyrische Darstellung gewidmet wird, die ich Ihnen nicht vorenthalten möchte, zählt diese Passage doch zum Bemerkenswertesten und Schönsten, was die Feder des jungen Hostos verfasst hat. Es handelt sich um die komplette Eintragung vom 27. Februar in Bayoáns Tagebuch:

27. Februar

Welch großartiger Sonnenuntergang! Die Sonne ist untergegangen: Ihr letzter Strahl, mit den Schatten kämpfend, färbt den Horizont: Und dieser sich verbreitende Strahl bringt Wunder hervor. Dort ist das Meer aus Perlmutt, das ich so oft bewundert: und es umfassend ein Land von dunkler Farbe; dieses bevölkernd Tausende von Inseln, von Klippen, von Felsen; und es durchziehend federleichte Dämpfe, die in meinen Augen die Form von Schiffen besitzen.

Von dem es säumenden Land spross ein Gebirge empor: Welch ein Gebirge! Gibt es eines auf Erden, welches die Kühnheit nachahmt, mit der es sich im Raume erhebt? Gibt es eines, das seine Strömungen von Brillanten, seine tiefdunklen Sturzbäche, seine maßlosen Bäume, seine kolossalen Wälder, die Aureole nachahmt, die ihren Gipfel krönt? In der Nähe des Gebirges eine Höhle: Ich sehe ihre Tiefe im Glanze jenes purpurfarbenen Lichts: Und im Glanze dieses Lichtes sehe ich diese Phantasmen, diese seltsamen Ungeheuer, diese furchterregenden Schatten, welche in sie eindringen wollen und sich Seit an Seite drängeln und sich stoßend den Weg versperren, wobei sie sich schlagen, sich zerstören und ins Nichts zurückfallen oder sich verwandeln. Alles verschwindet dann wieder: Die Höhle und ihre Ungeheuer lösen sich auf; das Gebirge versinkt; das Meer aus Perlmutt bricht ein. An deren Stelle erscheinen leichte Formen, weiße Wölkchen, formlose Dämpfe, die umherschweben, oszillieren, sich bewegen und sich verbergen. Dort kommen die Schatten der Nacht: Als

49 Ebda., S. 245.

50 Ebda., S. 168. 


\begin{abstract}
erstes schwärzen sie den gegenüberliegenden Horizont, überrennen den Zenit, verdunkeln den Westen, lassen die letzten Farben schwinden, welche das Licht gelassen, färben den Himmel dunkel. Aus diesen Schatten wird im Osten ein helles Blau geboren, das im Westen dunkel ist: Ein Stern taucht auf, danach ein anderer, jetzt schon tausend. Nacht herrscht: Weder Farben noch Schatten, keinerlei Dämpfe im Sonnenuntergang. Alles ward dunkel: Und jetzt ist nichts ... Doch! In meinem Hirn entsteht ein trauriger Gedanke, ein bitterer Vergleich. Die Einbildungskraft ist eine Sonne, welche ewig untergeht: Sie bringt eine Welt hervor, färbt sie im Glanze ihres unsichtbaren Feuers, und sobald sie es vervollkommnet, verbirgt sich ihre Welt hinter einem Flug, der Dampf einer unrettbaren Nacht verdunkelt sie, und die Dunkelheit lässt sie wieder verschwinden. Am Himmel erinnern die Sterne das Licht der schon untergegangenen Sonne: In der Einbildungskraft bleibt nichts; die Luft ist nichts. $^{51}$
\end{abstract}

Ich habe Ihnen diese Eintragung in Bayoáns Bordbuch in voller Länge vorgestellt, damit Sie einen anschaulichen Eindruck von der Gestaltung des Textes als einzelne poetische Fragmente erhalten. Darüber hinaus zeigt diese Passage in ihrer lyrischen Dichte fundamentale Strukturen einer romantischen Ästhetik auf, in welcher die Einbildungskraft des Dichters am meisten zur Konzeption und Generierung des Textes beiträgt. Wirklichkeit, Tagtraum und freie Fantasie erzeugen Bilder, die sich wechselseitig überlagern, wobei sich die Grenzen zwischen Realität, Fiktion und Leben auflösen: Alle Bilder, ob sie nun von der Wirklichkeit oder der Fiktion generiert und geliefert werden, sind auf der Ebene des Lebens wie des Erlebens gleich intensiv.

Zunächst gilt es festzuhalten, dass das Meer in seinen Bewegungen auch die Satzstrukturen, die ständige Wiederholung in Varianz abbildet: Es handelt sich um grammatikalische Parallelstrukturen, welche - die lyrische Prosa rhythmisierend - eingesetzt werden. Wie Wellen brechen sich im Text, Welle auf Welle, die einzelnen Satzglieder. Die Entwicklung dieser gesamten Passage ist auf den Übergang von einer Welt ins Nichts, in das „Nada“ gerichtet: zuerst das Meer in den verschiedensten Farben und Bewegungen, eine Welt des Festlandes vorgaukelnd, mit ihren Bergen, ihren Bäumen, ihren Wäldern, all jenem, was in absolutem Gegensatz zum Wasser steht. Dann das allmähliche Verschwinden dieser Welt, ihr Eintauchen ins Meer, ihr Eintauchen schließlich in die Nacht, wo die Sterne als Reflex des Verschwundenen, der untergegangenen Sonne allein am Himmel zurückbleiben.

Alles erweist sich als Spiel der Einbildungskraft, der Imagination im Hirn des Dichters; doch wird auch deren buntes, ständig wechselndes Spiel schlussendlich ,bitter zurückgenommen ins Nichts der Nacht, ins Ende des fantastischen

51 Ebda., S. 175. 
Schreibens. Ständige Bewegung, unabschließbare Mobilität, vom Ich des Lyrikers gespiegelt, und doch letztlich gänzlich aufgehoben, ins Nichts führend und sich auflösend: Eben dies ist auch die Bewegung von Bayoán selbst. Die Spiegelfläche des Meeres erscheint als Projektionsfläche, die des Lichts bedarf: Sie ist wie eine Leinwand, die in unterschiedliches Licht getaucht wird und auf welcher sich ständige Bewegungen, seltsame Wesen und Ungeheuer, aber auch Unkörperliches und Luftiges in freiem Farbenspiel abbilden lassen. Das Meer ist ständige Bewegung und doch immer gleich: Jede Welle ist neu, war noch nie da und wird auch nie mehr sein, öffnet sich zugleich aber auf ein Künftiges, das in seinen Formen noch unvorhersehbar bleibt. Es erscheint analog zur Projektionsfläche der Einbildungskraft im Innern des Ich, auf der Leinwand der Imagination. Natur und Mensch, Projektionsfläche und Einbildungskraft werden so dialogisch und zugleich harmonisch aufeinander bezogen und lösen sich auf der Seite des Menschen am Ende - denn so ist die Conditio humana - ins Nichts auf.

Der zitierte Tagebucheintrag aus La Peregrinación de Bayoán zählt zweifellos zu den schönsten Passagen nicht allein dieses Romans, sondern des Schreibens von Eugenio María de Hostos insgesamt. Es fällt mir an dieser Stelle schwer, der Verlockung zu widerstehen, Ihnen sogleich Bezüge zu einem anderen Autor der spanischsprachigen Karibik, dem Kubaner Reinaldo Arenas vorzuhalten. Ich habe letzterem bereits ein Kapitel in meiner Vorlesung zum 20. Jahrhundert ${ }^{52}$ sowie vor langen Jahren einen Band gewidmet, der Ihnen einen Überblick über sein gesamtes Schreiben erlaubt. ${ }^{53}$

Auch bei Arenas ist die Nacht jenes Element, das dem wahnwitzigen Spiel der Imagination, die das Leben ist, ein Ende (vielleicht sogar ein erlösendes Ende) bereitet. Antes que anochezca, seine Autobiographie Bevor es Nacht wird, ist hierfür die Formel eines sich in vielen verschiedenen Zyklen vollziehenden Schreibens, das stets von Dunkelheit, von Lichtlosigkeit bedroht ist und doch in diese alles umgebende Dunkelheit seine schillernden Projektionen sprüht. In seinem Roman Otra vez el mar finden wir als Hauptfigur das Meer wieder, das mit seinen Zyklen, seiner ständigen Wiederkehr des immer wieder Anderen gleich zu Beginn des Romans brillant in Szene gesetzt wird. Auch in der nachfolgenden Passage ist es eine fluktuierende Fläche, die nicht auf ein Einziges, eine wie auch immer geartete feste Identität reduziert werden kann, sondern sich in ständiger, unabschließbarer Bewegung befindet sowie die eigene Gestalt wie Proteus unablässig transformiert:

52 Vgl. Ette, Ottmar: Von den historischen Avantgarden bis nach der Postmoderne, S. 811-829. 53 Vgl. Ette, Ottmar (Hg.): La escritura de la memoria. Reinaldo Arenas: Textos, estudios y documentación. Segunda edición. Frankfurt am Main - Madrid: Vervuert - Iberoamericana 1996. 


\begin{abstract}
Das Meer. Blau. Am Anfang nicht. Am Anfang ist es eher gelb. Aschgrau, würde ich sagen ... Obwohl es auch nicht aschgrau ist. Weiß, vielleicht. Weiß heißt nicht durchsichtig. Weiß. Aber danach, wenn auch fast noch am Anfang, wird es grau. Grau, eine Zeitlang. Und danach dunkel. Voller Furchen, die noch dunkler sind. Ritzungen im Wasser. Es mögen vielleicht die Wellen sein. Aber nein: allein Spiegelungen des Wassers, dazu die Sonne. Wären es Wellen, würden sie bis zur Küste kommen. Das heißt bis zum Sand. Doch es gibt keine Wellen. Allein das Wasser. Das fast tollpatschig das Land schlägt. Doch es schlägt nicht. Würde es schlagen, so müsste man irgendein Geräusch hören. Es herrscht Stille. Allein das Wasser, wie es das Land berührt. Ohne es zu schlagen. Es kommt, weiß, nicht durchsichtig, berührt es tollpatschig und entfernt sich. Es ist nicht das Land: Es ist der Sand. Wenn das Wasser ohne Wellen ansteigt, dann entsteigt dem Sand vielleicht ein Geräusch. Befriedigte Erde. Von hier aus höre ich nichts. Das Wasser steigt, aber man sieht es nicht wieder fallen. Der Sand absorbiert es. Darunter fließt es zurück ins Meer ... Und weiter draußen ist es nicht mehr grau, sondern braungrau. Sehr dunkel. Fast schwarz. Bis es am Ende wirklich schwarz ist. Aber es ist schon sehr hoch. Es vereinigt sich mit dem Himmel. Voneinander getrennt lassen sich die beiden nicht unterscheiden. So dass es schließlich, wenn man es fixiert, niemals blau ist ... ${ }^{54}$
\end{abstract}

Auch in dieser Passage des kubanischen Schriftstellers sind die Bewegungen des Wassers in den Bewegungen der Sprache in nachahmender Formgebung dargestellt. Kleine Welle folgt auf kleine Welle, dazwischen größere Wellen, die den Sand, „la arena“ berühren - ein offenkundiges Spiel mit dem eigenen Nachnamen des Autors, der sich vom Meer liebevoll berührt weiß und auch in dieser Szenerie seine Geschlechtlichkeit, seine in Kuba zum Zeitpunkt der Romanhandlung verfolgte Homosexualität bewusst vieldeutig ausspielt. Das Meer erscheint schillernd in seinen ständigen Metamorphosen, in seinen unabschließbaren Transformationen als das, was im Griechischen dem Archipel seinen Namen gab: nicht das Land der Inseln, sondern das zwischen ihnen liegende, sie zugleich trennende und miteinander verbindende Meer.

Im Incipit von Reinaldo Arenas' Roman wird das gesamte Spektrum zwischen Weiß und Schwarz mit Ausnahme des Blauen und Transparenten abgeschritten. Nur das Konventionelle also - das Meer ist gemeinhin blau, das Wasser transparent - wird ausgeschlossen und negiert. Der Blick ist in dieser Passage freilich der vom Land auf das Meer, nicht wie bei Hostos der vom Meer aus auf ein Meer, das wie Land erscheint. Bei Arenas ist es das unzugängliche, jedwede Verbindung unterdrückende Element, das ein Eingesperrt-Sein auf der Insel vom Politischen ins Naturhafte verlängert. Und zugleich ist es das Gedächtnis, dessen Fluktuationen und Zyklen, dessen Abarbeiten an der Grenze zwischen Erde und Wasser beständig nachvollzogen und versinnbildlicht werden.

54 Arenas, Reinaldo: Otra vez el mar. Barcelona: Editorial Argos Vergara 1982, S. 9. 
Aus der Differenz beider Inszenierungen des Meeres wird deutlich, wie sehr es für den der Romantik noch verpflichteten Hostos eine Projektionsfläche für die Phantasie ist, deren Gestalten und Formen die See inspiriert und aufnimmt. Das Meer mit seinen Wellen steht als Metapher für das Leben und den Menschen selbst, von dem der Protagonist des Romans auch sagt, dass sein Inneres von Wellen durchzogen sei. Zugleich drückt es als Metapher des Imaginären und der Imagination die unergründliche Tiefe des menschlichen Geistes und Bewusstseins aus. Das Meer wird gleichsam zur Chiffre des Selbstverständnisses von Imagination und Schreiben in der Karibik. Als vom Menschen nicht dauerhaft bewohnbare Anökumene wird es mit phantasievollen Gestalten und gefährlichen Ungeheuern bevölkert, so wie die mittelalterlichen Kartenbilder auf ihren weißen, dem Meer gewidmeten Stellen die ausgefallensten Seemonstren verzeichneten.

Doch kehren wir nochmals zurück zum Romangeschehen: Mariéns Krankheit, die mit der Melancholie begann und sich mit Albträumen fortsetzte, verschlechtert sich. Es ist eine Krankheit zum Tode, eine romantische Krankheit überreizter Empfindsamkeit, welche für die weibliche Hauptfigur fatale Folgen hat. Die zuvor völlig unterdrückte Körperlichkeit macht sich unversehens bemerkbar: Erst wird durch eine (un)geschickte Bewegung der Busen der schönen Kubanerin entblößt, dann wieder wird sie durch einen Kuss in einen psychischen Rückfall gestürzt, und schließlich - nach der Hochzeit in extremis und kurz vor ihrem Ende - werden beide Situationen zu einer einzigen kumuliert. Denn der nun zum Ehemann gewordene Bayoán betrachtet während einer Nachtwache die Todkranke und erfreut sich am Anblick ihres freilich bedeckten Busens.

Dieser Voyeurismus hat Folgen: Marién, die Augen aufschlagend, sieht den Blick ihres Mannes, erschrickt und stößt einen schrecklichen Schrei aus. ${ }^{55} \mathrm{Ihr}$ Ende ist nun nahe, und die Leserschaft - heutzutage psychoanalytisch geschult weiß, wie sehr die unterdrückte und nicht sublimierte Sexualität zum Fortschreiten der romantischen Krankheit beigetragen hat und weiter beiträgt. Marién ist kein Engel, da sie im Gegensatz zu Engeln eine prononcierte Geschlechtlichkeit besitzt. Doch als diese im wahrsten Sinne des Wortes ent-deckt oder aufgedeckt ist, wird auch der Verlauf der tödlichen Krankheit beschleunigt. In den Augen Bayoáns ist sie „angelical“ und „divina“, also engelgleich und göttlich; doch wird dieses Bild gerade in der Nähe zum Tod durch die Körperlichkeit der Protagonistin sexualisiert und sogleich tabuisiert: Eros und Thanatos finden zusammen.

Mariéns fatale Krankheit schreitet voran; und sie kommt - wie jede romantische Krankheit - von innen. Es handelt sich diesmal nicht um einen Blutsturz, den wir bei männlichen Protagonisten im lateinamerikanischen Roman am Bei-

55 Hostos, Eugenio María de: La Peregrinación de Bayoán, S. 302. 
spiel von El Matadero oder Sab beobachten konnten, sondern um innere Konvulsionen, wohl epileptischen Anfällen vergleichbar, die das junge Mädchen ungeheuer schwächen. Ein Arzt versucht uns zu erklären, dass die Krankheit auf den angedrohten Liebesentzug, auf die Melancholie, noch immer das „Mal du siècle,“ ja auf die Trennung vom Vaterland zurückgehe, wobei all dies einen Erregungszustand ausgelöst habe, der das Leben Mariéns bedrohe. ${ }^{56} \mathrm{Ihr}$ Gesundheitszustand wird so ernst, dass sich ihr Mann nicht einmal mehr erlaubt, sie zu küssen, führte doch ein unvorsichtiger Kuss zu einem sofortigen und dramatischen Rückfall der Liebeskranken Melancholikerin. ${ }^{57}$

Vor dem Hintergrund dieser Entwicklung bleibt dem Protagonisten nur die männliche „desesperación de mi impotencia“, ${ }^{58}$ die Verzweiflung angesichts seiner eigenen Impotenz. Einig aber sind sich die Verliebten und frisch Vermählten in ihrer Nostalgie Amerikas, blicken sie doch beide gen Westen und denken sehnsuchtsvoll an Kuba und Puerto Rico. ${ }^{59}$ Sein Versprechen, Marién bald zu ihrer Insel zurückzuführen, kann Bayoán aufgrund ihres Todes nicht mehr einlösen. So wird er selbst am Ende des Romans einsam nach Amerika zurücksegeln, um dort eine Republik zu finden, wo er sich niederlassen könnte. Doch selbst diese kleine Hoffnung ist ungewiss; er denkt bereits daran, dass angesichts der Situation in den Republiken der iberisch geprägten Welt ein fortdauerndes Pilgerleben sein Los sein werde - Hostos' Kritik an der Entwicklung der politisch unabhängig gewordenen, aber noch immer unfreien Länder Hispanoamerikas ist auch an anderen Stellen von La Peregrinación de Bayoán unübersehbar.

So endet wenig tröstlich der erste und einzige Roman jenes puerto-ricanischen Intellektuellen, der auf beeindruckende Weise in seinem künstlerischen Schaffen die Romantik in der Literatur mit dem „Krausismo“ und Positivismus in der Philosophie verband. In seinen späten Jahren stellte er ein gedankliches Bindeglied zum Idealismus und mehr noch Arielismus in einem Zwischenbereich zwischen Philosophie und Literatur dar. Die Bedeutung dieses Schriftstellers aus Puerto Rico kann in den genannten Zusammenhängen kaum überschätzt werden. Denn er schlug damit eine Brücke zwischen der Mitte des 19. Jahrhunderts und dem Beginn des 20. Jahrhunderts, verbindet gleichsam die Generationen von Gertrudis Gómez de Avellaneda oder Domingo Faustino Sarmiento mit denen von José Martí, José Enrique Rodó oder der Brüder Henríquez Ureña miteinander.

56 Ebdfa., S. 281.

57 Ebdas., S. 292.

58 Ebda.

59 Ebda., S. 286. 
Mag sein, dass - wie sein Schüler Pedro Henríquez Ureña einmal behauptete - Eugenio María de Hostos die Dichter aus seinem Staat ausgewiesen habe, weil sie nichts zu dessen Konstruktion beitrügen: Das Misstrauen gegenüber der literarischen Fiktion ist bei dem puerto-ricanischen Autor mit Händen greifbar. Doch es steht fraglos fest, dass Hostos selbst zum Bau der Literaturen Lateinamerikas wichtige Elemente und Baupläne beisteuerte. Er trug vor allem zur Anlage und Ausgestaltung jenes Diskurses bei, den die Lateinamerikaner von Lateinamerika aus über ihren Kontinent gegen Ende des 19. Jahrhunderts entwickelten. Jener Mann, der vom spanischen Romancier Benito Pérez Galdós als „,antillano de ideas radicales“, als Antillaner von radikalen Vorstellungen bezeichnet worden ist, hatte wohl für die Bildung einer Antillanischen Föderation, nicht aber für die kulturelle Loslösung von Spanien plädiert. La peregrinación de Bayoán ist hierfür ein beredtes Beispiel.

Einen Unterschied zwischen politischer, sozialer und literarischer Kritik gab es für Hostos nicht. So bietet das Frühwerk des Romanciers aus Puerto Rico für diese Ebenen und Diskurse vielfältige und gleichwertige Anknüpfungspunkte. Die Pilgerschaft Bayoáns ist die Suche nach einer neuen gesellschaftlichen Ordnung, die im Verlaufe des Romans jedoch nicht zustande kommt. Das Motiv erfolgloser Pilgerschaft ist uns in unserer Vorlesung bereits mehrfach begegnet und wird uns bei dem philippinischen Schriftsteller José Rizal ein weiteres Mal beschäftigen. Auch Bayoáns Projekt einer gütlichen Einigung mit der Kolonialmacht Spanien scheitert. Und man könnte hinzufügen: Da das Spanien der Conquista und der kolonialen Unterdrückung nicht weichen will, schickt sich bereits eine andere Macht an, das alte Kolonialreich durch ein eigenes imperiales Reich zu ersetzen, das ebenso aus militärischen wie aus wirtschaftlichen Gründen prosperiert. Dies aber wird eine Erfahrung sein, mit welcher wir uns erst gegen Ende unserer Vorlesung zu beschäftigen haben werden und welche die hispanoamerikanischen Modernisten rund um die Ereignisse von 1898 mit vielerlei Sorgen, aber auch mit manchen Hoffnungen erfüllen sollte. 